\title{
Review of Transporter Substrate, Inhibitor, and Inducer Characteristics of Cladribine
}

\author{
Robert Hermann ${ }^{1}$ (D) Peter Krajcsi ${ }^{2} \cdot$ Markus Fluck $^{3} \cdot$ Annick Seithel-Keuth $^{3} \cdot$ Afrim Bytyqi $^{3} \cdot$ Andrew Galazka $^{3}$. \\ Alain Munafo ${ }^{4}$
}

Accepted: 28 July 2021 / Published online: 26 August 2021

(c) The Author(s) 2021

\begin{abstract}
Cladribine is a nucleoside analog that is phosphorylated in its target cells (B- and T-lymphocytes) to its active adenosine triphosphate form (2-chlorodeoxyadenosine triphosphate). Cladribine tablets $10 \mathrm{mg}$ (Mavenclad ${ }^{\circledR}$ ) administered for up to 10 days per year in 2 consecutive years $(3.5-\mathrm{mg} / \mathrm{kg}$ cumulative dose over 2 years) are used to treat patients with relapsing multiple sclerosis. The ATP-binding cassette, solute carrier, and nucleoside transporter substrate, inhibitor, and inducer characteristics of cladribine are reviewed in this article. Available evidence suggests that the distribution of cladribine across biological membranes is facilitated by a number of uptake and efflux transporters. Among the key ATP-binding cassette efflux transporters, only breast cancer resistance protein has been shown to be an efficient transporter of cladribine, while P-glycoprotein does not transport cladribine well. Intestinal absorption, distribution throughout the body, and intracellular uptake of cladribine appear to be exclusively mediated by equilibrative and concentrative nucleoside transporters, specifically by ENT1, ENT2, ENT4, CNT2 (low affinity), and CNT3. Renal excretion of cladribine appears to be most likely driven by breast cancer resistance protein, ENT1, and P-glycoprotein. The latter may play a role despite its poor cladribine transport efficiency in view of the renal abundance of P-glycoprotein. There is no evidence that solute carrier uptake transporters such as organic anion transporting polypeptides, organic anion transporters, and organic cation transporters are involved in the transport of cladribine. Available in vitro studies examining the inhibitor characteristics of cladribine for a total of 13 major ATP-binding cassette, solute carrier, and CNT transporters indicate that in vivo inhibition of any of these transporters by cladribine is unlikely.
\end{abstract}

\section{Key Findings}

The cladribine tablet is an oral therapy for people with relapsing multiple sclerosis.

In this comprehensive review, the authors look at the role of various transporter proteins in the absorption, distribution, and excretion of cladribine.

Robert Hermann

robert.hermann@cr-appliance.com

$1 \quad$ Clinical Research Appliance (cr.appliance), Heinrich-Vingerhut-Weg 3, 63571 Gelnhausen, Germany

2 Habilitas Kft, Budapest, Hungary

3 Merck Healthcare KGaA, Darmstadt, Germany

4 Institute of Pharmacometrics, an Affiliate of Merck KGaA, Lausanne, Switzerland

\section{Introduction}

Multiple sclerosis (MS) is a chronic and debilitating autoimmune disorder of the central nervous system, affecting about 2.8 million people worldwide [1]. B- and T-lymphocytes are believed to play a major role in the pathophysiology of MS [2]. Cladribine tablets $10 \mathrm{mg}$ (Mavenclad ${ }^{\circledR}$; Merck Europe B.V., Amsterdam, Netherlands), were shown to have significant efficacy in the treatment of relapsing MS in placebo-controlled phase III trials [2-4]. A cumulative dose of $3.5 \mathrm{mg}$ per $\mathrm{kg}$ body weight (consisting of two annual courses each comprising two treatment weeks; at the start of the first month and at the start of the second month of each year) has been approved for the treatment of adults with certain types of relapsing MS [5]. Treatment with cladribine results in selective reductions in B-lymphocyte and T-lymphocyte counts. Historically, emphasis has been placed predominantly on 
T-cell inhibition as the main hypothesized mechanism of action. However, more recent immunophenotyping data demonstrated that effective doses of oral cladribine only induced a $20-30 \%$ reduction in $\mathrm{CD} 8^{+} \mathrm{T}-$-lymphocytes and a 40-45\% reduction in $\mathrm{CD} 4{ }^{+} \mathrm{T}$-lymphocytes during the first 12 months after initiation of treatment. This was accompanied by a comparable reduction in memory T-lymphocytes, but induced a marked reduction $(80-85 \%)$ in CD19+ B-lymphocytes [6,7]. Current evidence suggests that cladribine primarily confers a long-lasting B-lymphocyte reduction characterized by slow repopulation kinetics, along with long-term memory B-lymphocyte reduction [8]. This mechanism suggests that cladribine acts as an immune-reconstitution therapy inducing immune resetting and results in long-term efficacy. The short-term treatment posology of cladribine tablets with subsequent treatmentfree periods has the potential to facilitate patient adherence [9], which is still an existing challenge for the longterm treatment of MS [10].

\subsection{Mechanism of Action}

Cladribine is a chlorinated analog of deoxyadenosine. The chlorine substitution renders cladribine largely resistant to deamination by adenosine deaminase, prolonging its presence and leading to accumulation in the cell cytoplasm [11]. Cladribine is a prodrug that is phosphorylated intracellularly to its active form, 2-chlorodeoxyadenosine triphosphate (2-Cd-ATP). Formation of 2-Cd-ATP is a sequential three-step process: first, cladribine is phosphorylated to 2-chlorodeoxyadenosine monophosphate (2-Cd-AMP) by nuclear/cytosolic enzyme deoxycytidine kinase (DCK) and mitochondrial deoxyguanosine kinase. 2-Cd-AMP is then further phosphorylated by nucleoside monophosphate kinase to 2-chlorodeoxyadenosine diphosphate (2-CdADP), and nucleoside diphosphate kinase to 2-Cd-ATP. In most cells, 2-Cd-AMP is dephosphorylated by 5 '-nucleotidase ( $\left.5^{\prime}-\mathrm{NT}\right)$ and, consequently, accumulation of 2-CdATP depends on the intracellular ratio of DCK and $5^{\prime}$-NT enzymes. Cells with high endogenous DCK/5'-NT activity ratio (as is the case in B- and T-lymphocytes) accumulate deoxynucleotides to toxic concentrations, resulting in cell death. By this mechanism, cladribine exerts a selective mode of action on B- and T-lymphocytes [12,13]. Thus, constitutive variations in the expression levels of DCK and $5 '$-NT between immune cell subtypes explain differences in immune cell sensitivity to cladribine. Accordingly, cells of the innate immune system are less affected than cells of the adaptive immune system [13, 14]. The preferential reduction in lymphocyte subpopulations, followed by the pattern of lymphocyte recovery (termed immune reconstitution), may 'reset' the immune system to a less autoreactive state [15].

\subsection{Biopharmaceutical Characteristics and the Role of Transporters in the Disposition of Cladribine}

As a nucleoside analog, cladribine represents a small hydrophilic compound (molecular weight $285.7 \mathrm{~g} / \mathrm{mol}$ ). Cladribine has been shown to have a moderate permeability with an apical to basolateral (A-to-B, i.e., mimicking absorption) apparent permeability coefficient (i.e., $P_{\text {app }}$ value) of $0.95 \pm 0.05 \times 10^{-6}$ $\mathrm{cm} / \mathrm{s}$ in colorectal adenocarcinoma-2 (Caco-2) cell monolayers, about five-fold to six-fold greater than the $P_{\text {app }}$ value of atenolol (a low-permeability drug), and about six-fold lower than the $P_{\text {app }}$ value of minoxidil (a high-permeability drug) [data on file, Study Report DMPK 153-08; Merck KGaA, Darmstadt, Germany]. The rapid absorption of cladribine (time to maximum concentration of approximately $0.5 \mathrm{~h}$ ) does not seem to be capacity limited [5]. Cladribine has a topological polar surface area of $119 \AA^{2}$ and a $\log P$ of -0.1 . As a general rule, it is thought that neutral drugs with a topological polar surface area less than $100 \AA^{2}$ will permeate membranes with a high rate of passive diffusion, whereas drugs with a topological polar surface area greater than $140 \AA^{2}$ will not. Cladribine falls between these cut-offs, thus some uptake by passive diffusion seems possible. However, as a nucleoside analog, cladribine requires, in principle, transporter-mediated cellular uptake to exert its action on intracellular functions.

Cladribine has also been classified according to the Biopharmaceutics Drug Disposition Classification System as a Class II drug where efflux transporters may play a role in absorption [16]. Absorption and distribution of cladribine across biological membranes is facilitated by a variety of uptake and efflux transport proteins. The available evidence on the key transporters involved in the uptake and efflux of cladribine in target cells, in absorption and excretion processes in the intestine, liver, and kidney, and in the endothelium of the blood-brain barrier (BBB) and choroid plexus (CP) is reviewed in this article, as well as the potential of cladribine to elicit transporter-based drug interactions.

\section{Search Methodology}

Data from proprietary in vitro transporter studies conducted by or on behalf of Merck KGaA, Darmstadt, Germany, as well as a systematic review of literature and database entries on transporters are presented in this article. This review considers the role of concentrative nucleoside transporters (CNT1; CNT2; CNT3), and equilibrative nucleoside transporters (ENT1; ENT2; ENT4), as well as selected other uptake transporters from the solute carrier (SLC) superfamily and key ATP-dependent efflux pumps from the 
ATP-binding cassette (ABC) superfamily. Their selection was based on available preclinical and clinical evidence and current regulatory guidance documents [17-19] indicating that these transporter proteins play important roles in the disposition of nucleoside analog drugs, drug interactions, and/or side effects.

The specific transporters discussed in this review include nine transporters from the SLC superfamily, grouped into organic anion transporters (OATP1B1; OATP1B3; OAT1; OAT2; OAT3; OAT4) and organic cation transporters (OCT1; OCT2; OCT3), as well as seven ABC transporters (P-glycoprotein [P-gp]/ABCB1; breast cancer resistance protein $[\mathrm{BCRP}] / \mathrm{ABCG} 2$; multidrug resistance protein 2 (MRP2)/ABCC2; MRP4/ABCC4; MRP5/ABCC5; MRP7/ $\mathrm{ABCC} 10$; and MRP8/ABCC11), and finally two multidrug and toxin extrusion (MATE) transporters (MATE1; MATE2K).

\subsection{Literature Database and Literature Search Strategy}

In May 2019, a systematic review of the transporter substrate, inhibitor, and inducer characteristics of cladribine was undertaken using Medline In-Process (PubMed) and limited to English-language publications. As target cell uptake and efflux are of particular relevance to the disposition (and efficacy) of cladribine, search terms included the keywords "Cladribine/2-CdA" and specific white blood cell (WBC) subsets. In parallel, another set of searches aimed to explore transporter expression profiles of WBCs using a combination of keywords including names of WBC subsets, and current or traditional names of the selected ENT/CNT, ABC, SLC, and MATE transporters.

To enable assessment of the transporter abundance and localization in organs and tissues of interest, targeted searches were performed for transporter expression studies (i.e., proteomics studies). Cladribine transporter interaction studies were also searched for and reviewed using keywords "cladribine/2-CdA" and names of transporters thought to transport nucleoside analogs in general or cladribine with an emphasis on confirmed inhibitors or inducers of transporters already known to be involved in the uptake or efflux of cladribine.

A further literature search was conducted to explore the role of intracellular metabolic activation/deactivation of cladribine in target cell toxicity of, and resistance to cladribine using the following search terms: drug transport/ transporters, nucleoside transport/transporters, nucleoside transport tumor cells, cladribine/2-CdA resistance, cladribine/2-CdA clinical studies, cladribine/2-CdA toxicology, and cladribine/2-CdA metabolism.

The database search yielded a total of 510 articles of potential relevance. Two authors (RH and $\mathrm{PK}$ ) reviewed the complete set of abstracts independently for relevance using pre-defined criteria for selection and de-selection of publications, and reconciled their assessments and discrepancies by mutual discussion. Following this process, 76 articles were considered relevant for this review. During the ongoing preparation on this manuscript (i.e., between May 2019 and December 2020), the authors continued to screen literature databases for relevant publications, and additional pertinent publications issued during this time period were considered for this review.

\subsection{Transporter Substrate Characteristics of Cladribine}

In vitro transport assessments have been undertaken based on data in transporter-specific expression systems or holistic systems using transporter-specific inhibitors. Details on the in vitro cell systems used for these studies, cladribine concentrations employed, substrates, and control substances used are summarized in Tables 1, 2, 3, 4, 5 and 6.

\subsection{Assessment of Transporter Inhibition by Cladribine}

The assessment of the potential clinical relevance of observed in vitro transporter inhibition by cladribine was determined based on calculation methods suggested by regulatory agencies [17-19]. For the assessment of potential drug-drug interaction (DDI) risks, the obtained in vitro data were interpreted in the context of cladribine in vivo exposure data, with a particular emphasis on the free fraction of the compound. Protein binding of cladribine in human plasma is about $20 \%$ [20]. The maximum cladribine in vivo exposure achieved at steady state after administration of recommended clinical doses of one or two cladribine 10-mg tablets is about $0.07-0.14 \mu \mathrm{M}(20-40 \mathrm{ng} / \mathrm{mL})$ and respective unbound maximum cladribine steady-state concentrations are about $0.112 \mu \mathrm{M}(32 \mathrm{ng} / \mathrm{mL})$. One micromolar of cladribine translates to $285.7 \mathrm{ng} / \mathrm{mL}$.

For the assessment of the potential of cladribine to inhibit intestinal efflux transporters such as P-gp and BCRP, the cutoff criterion $I_{\text {gut }} /$ ratio of the concentration of drug inhibiting transporter activity by $50 \%\left(\mathrm{IC}_{50}\right)$ or $K_{i} \geq 10$ was applied $[17,18]$, whereby $I_{\text {gut }}=$ dose of inhibitor $/ 250 \mathrm{~mL}, \mathrm{IC}_{50}=$ half-maximal inhibitory concentration, and $K_{i}=$ inhibitory constant. If only $K_{i}$ or $\mathrm{IC}_{50}$ values were available from specific studies, the $\mathrm{IC}_{50}$ was assumed to be equivalent to $2 \times$ $K_{i}$ when the substrate concentration is equal to the Michaelis-Menten constant $K_{\mathrm{m}}$ [21].

No formal calculation as to whether cladribine may act as an inhibitor of the hepatic uptake transporters OATP1B1 and OATP1B3 was undertaken, as OATP1B1/3 in vitro transporter inhibition by cladribine compared to rifampicin 


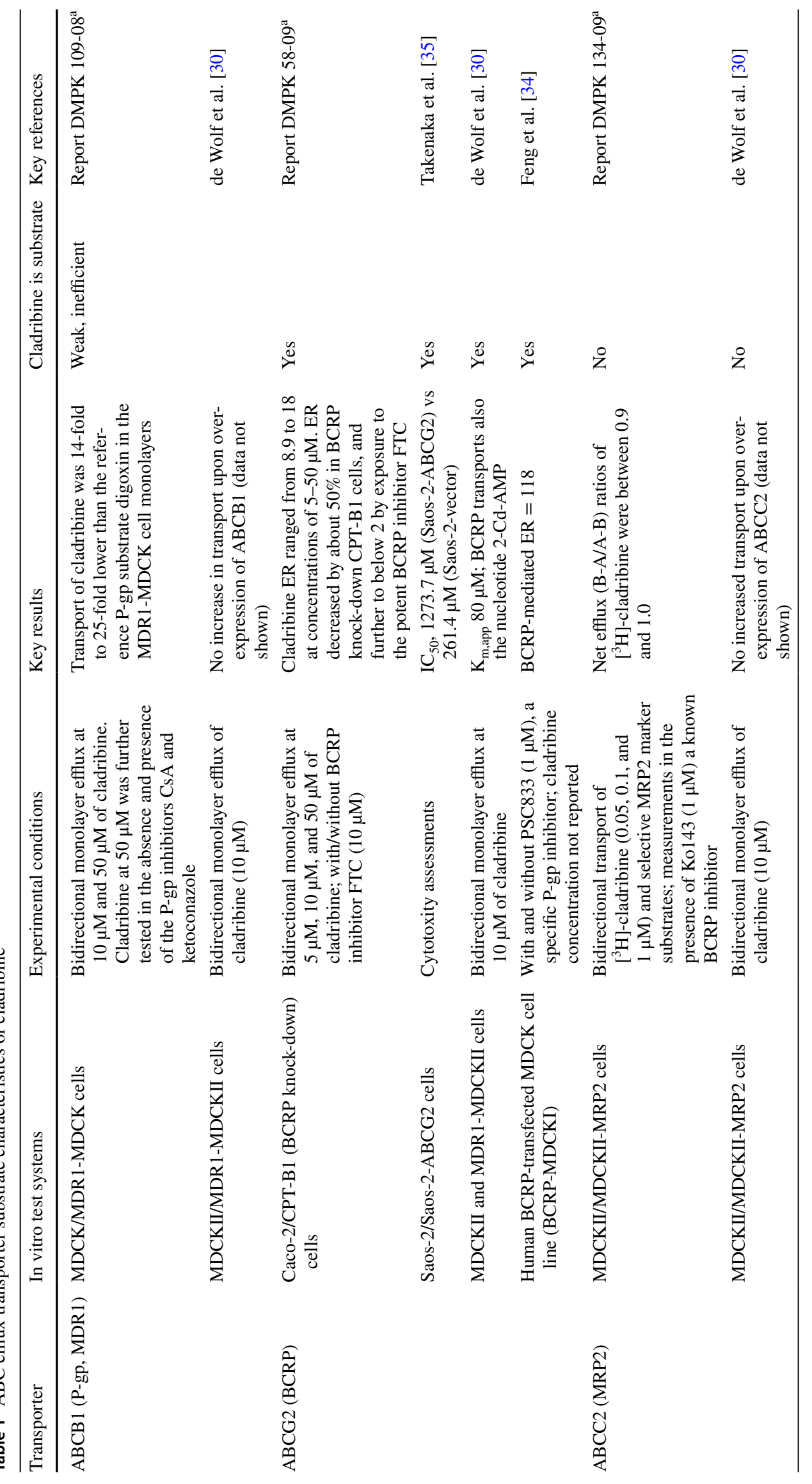




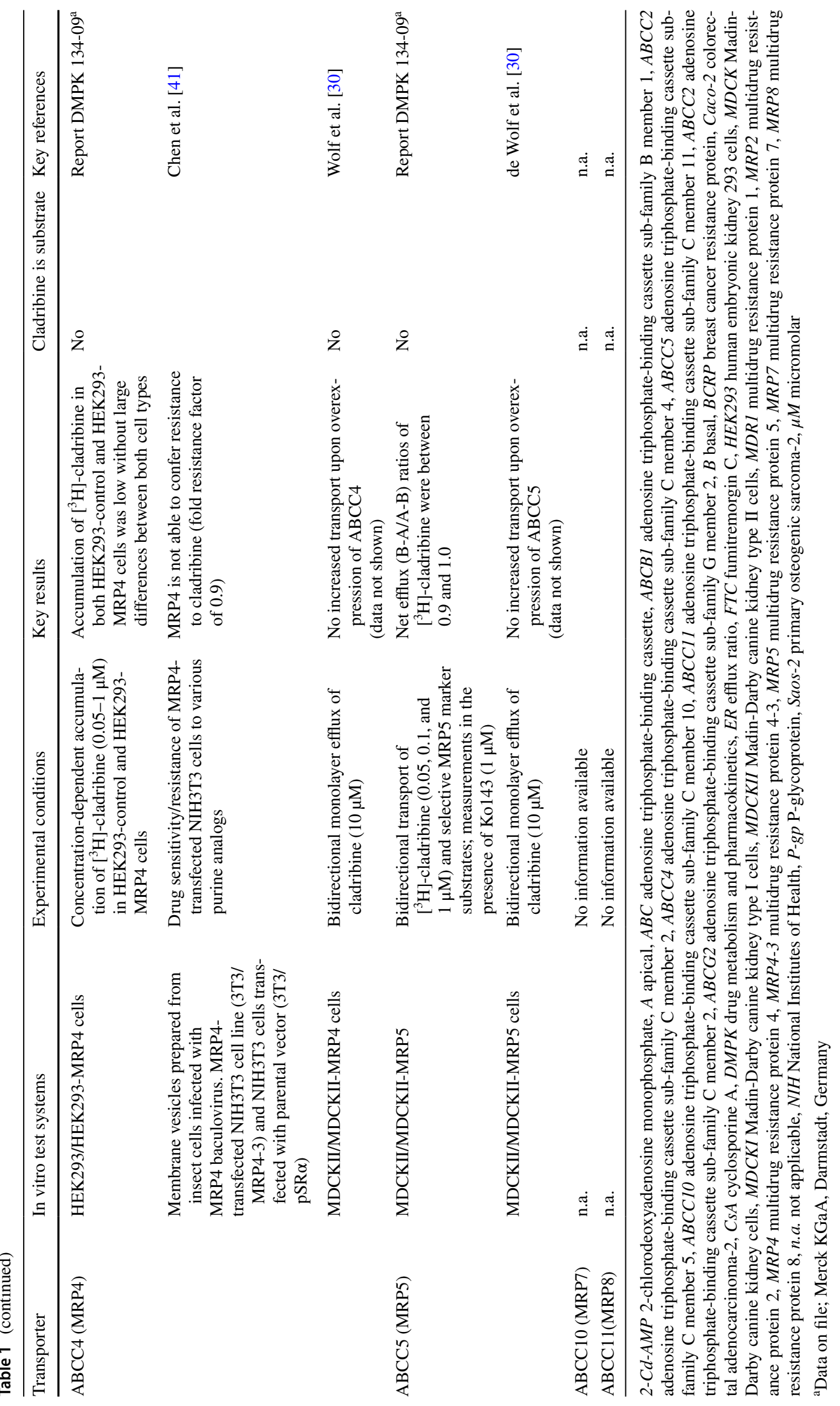




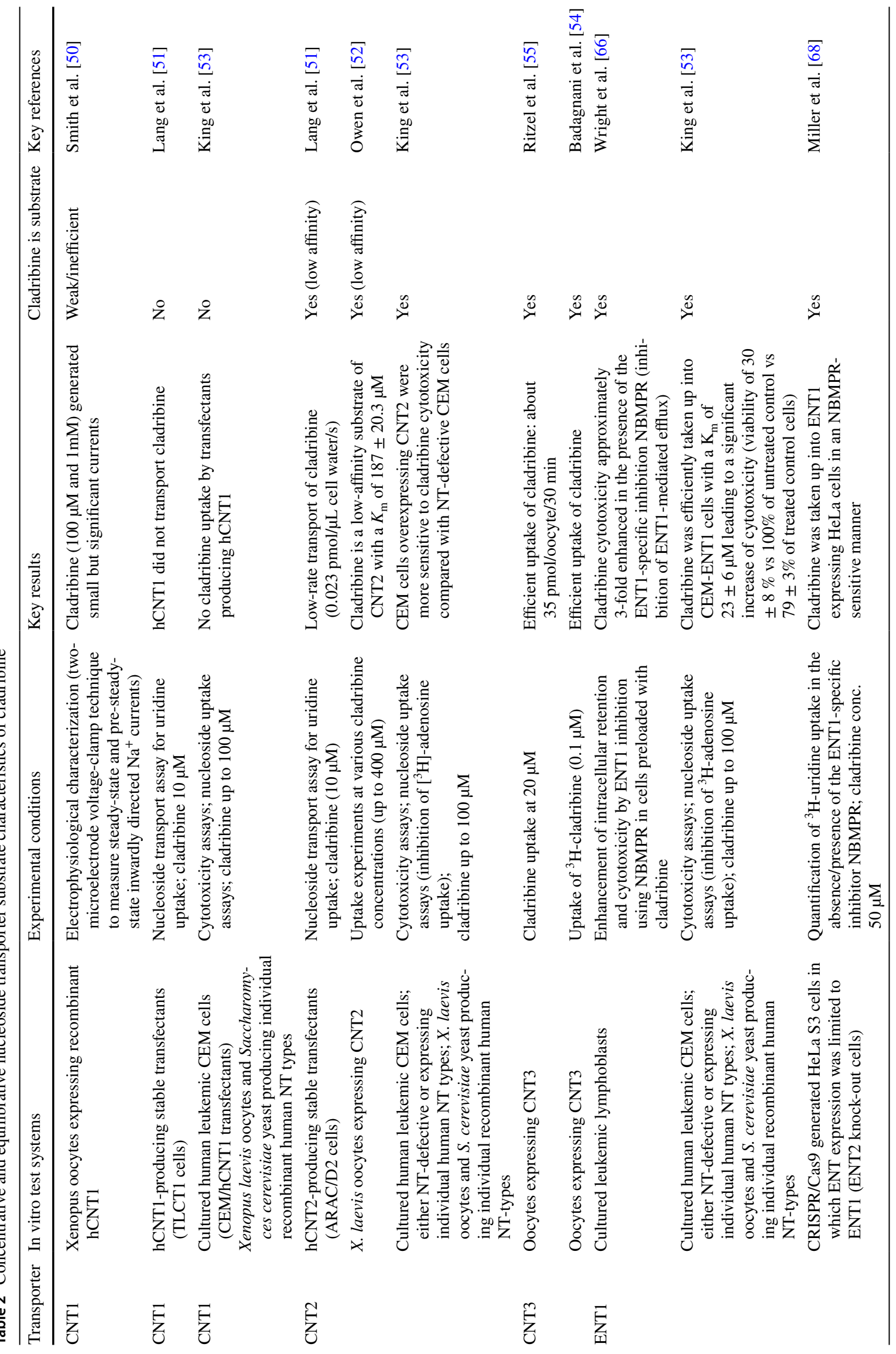




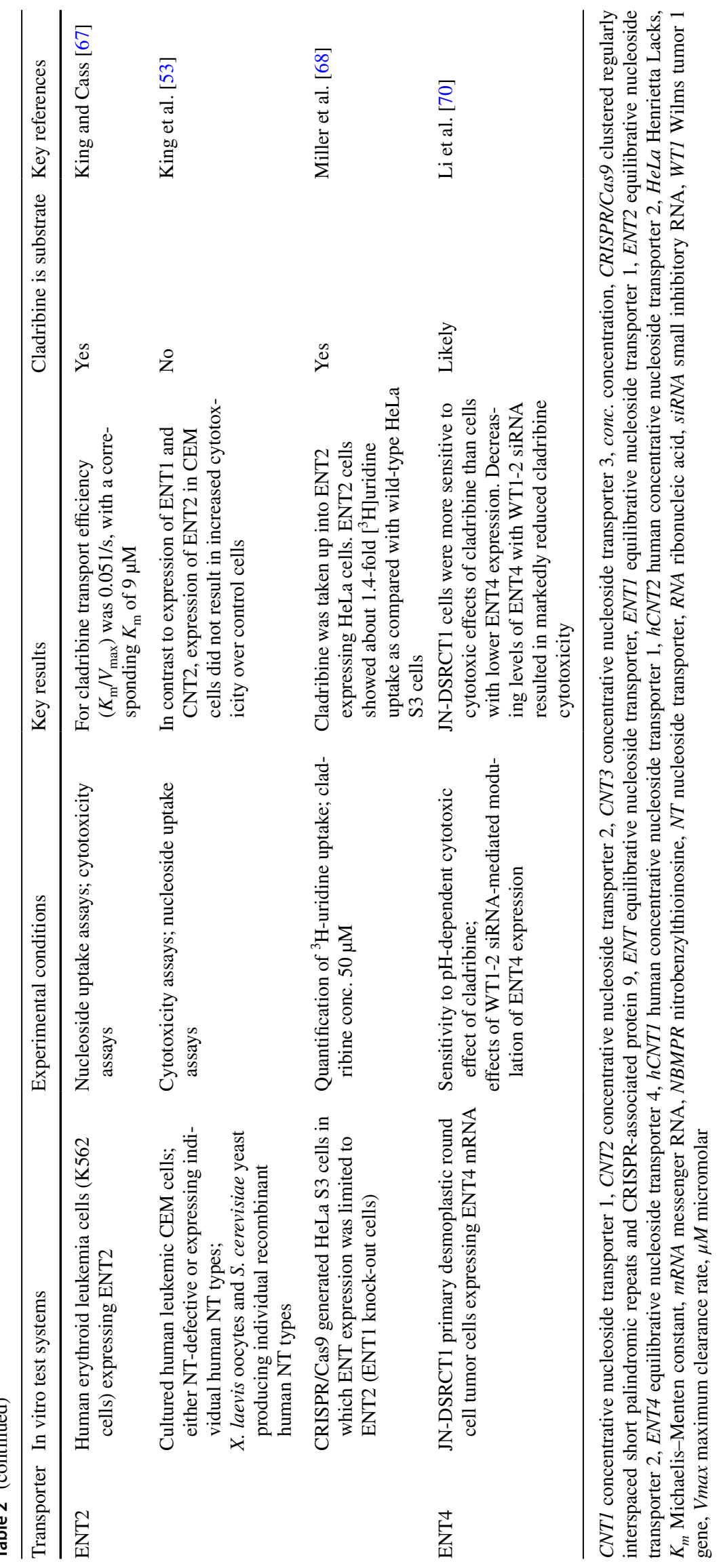




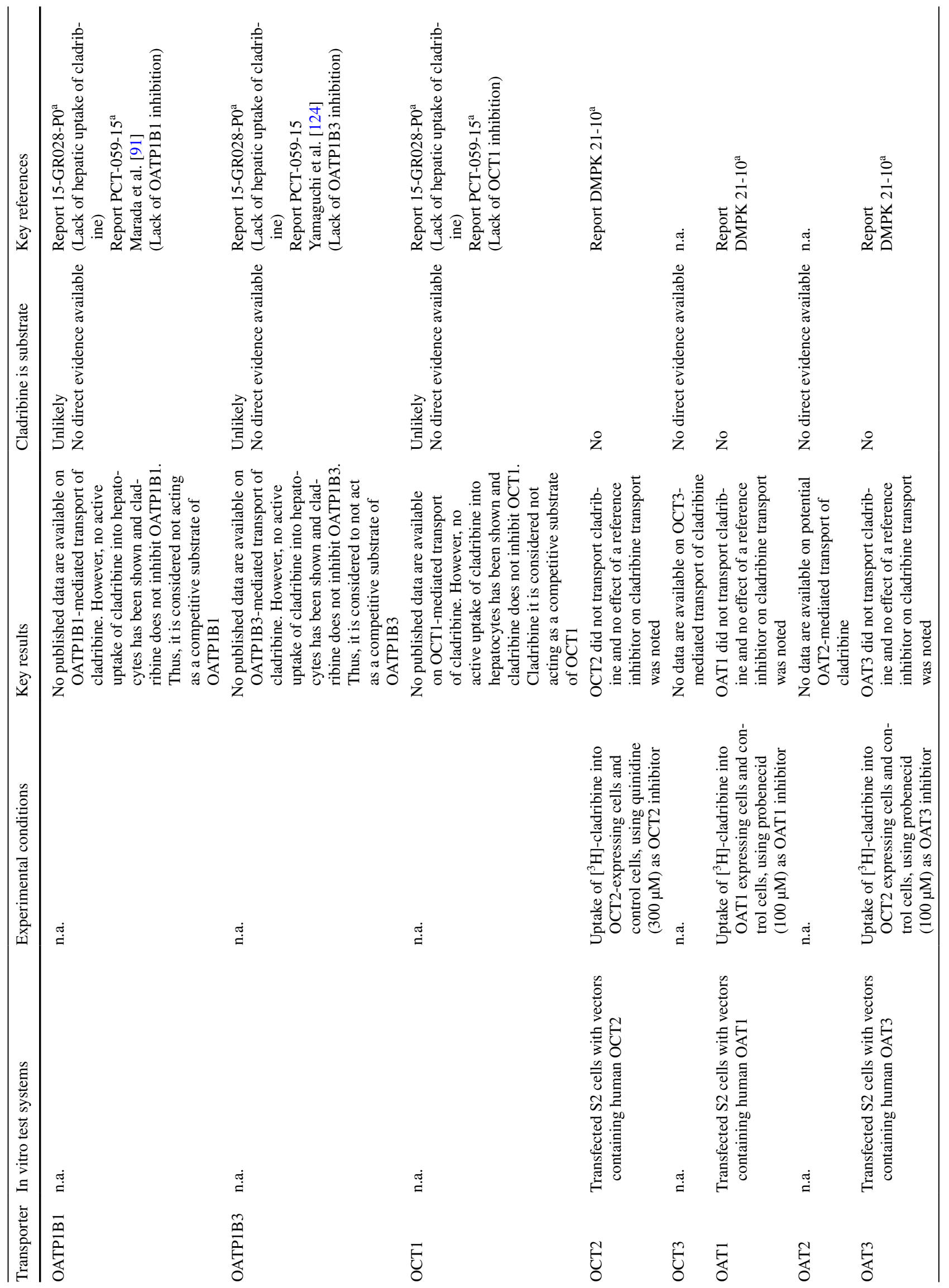


as a reference inhibitor was too low at all concentrations employed to derive $\mathrm{IC}_{50}$ or $K_{i}$ values (data on file, Study Report PCT-059-15; Merck KGaA). The in vivo potential of cladribine to inhibit OAT and OCT transporters was not formally assessed as in vitro transporter inhibition of OATs and OCTs by cladribine was either absent or too low to derive $\mathrm{IC}_{50}$ or $K_{i}$ values (data on file, Study Reports DMPK 131-09, PCT-059-15, and DMP K 21-10; Merck KGaA).

\subsection{ABC Efflux Transporters}

Efflux transporters are important determinants of substrate permeability across biological barriers as well as immune cells. The role of apical efflux transporters in barrier permeability has been thoroughly studied and documented [22], and will be briefly summarized below.

\subsubsection{P-gp/MDR1/ABCB1}

P-glycoprotein is expressed in all major barrier-forming cell types such as enterocytes, hepatocytes, kidney proximal tubule epithelial cells, and BBB endothelial cells [23, 24]. P-glycoprotein is localized at the apical membrane in all these cell types. The main physiological role of P-gp is protection of cells against toxins and xenobiotics.

Expression of P-gp in WBCs varies. According to quantitative polymerase chain reaction (qPCR) data in human lymphocytes of adults, $\mathrm{P}$-gp expression is intermediate among expressed ABC efflux transporters [25]. Among lymphocytes, $\mathrm{CD}^{+} \mathrm{T}$-lymphocytes and natural killer cells express higher levels than $\mathrm{CD} 4^{+}$T-lymphocytes and B-lymphocytes [26]. P-glycoprotein does not have many nucleoside analogs among its substrates [28], but transports some hydrophobic nucleoside analogs such as abacavir [29].

In the MDR1-Madin-Darby Canine Kidney (MDCK) system, cladribine displayed a net efflux ratio of 2.87 at $50 \mu \mathrm{M}$ that was inhibited below unity by cyclosporine A $(10 \mu \mathrm{M})$ and ketoconazole $(20 \mu \mathrm{M})$ [data on file, Study Report DMPK 109-08; Merck KGaA]. At $10 \mu \mathrm{M}$ of cladribine, the observed efflux ratio was 1.79 and, in another study, no increase in basal-to-apical permeability of ${ }^{3} \mathrm{H}$-cladribine was detected in MDCKII cells upon overexpression of P-gp [30]. Therefore, $\mathrm{P}-\mathrm{gp}$ is not considered to be an efficient transporter of cladribine.

\subsubsection{BCRP/ABCG2}

$\mathrm{BCRP} / \mathrm{ABCG} 2$ is a transporter restricting absorption and enhancing excretion of many compounds. BCRP is expressed in all major barrier-forming cell types such as enterocytes, hepatocytes, kidney proximal tubule epithelial cells, and BBB endothelial cells [23]. As an efflux pump, BCRP is apically located in all these cell types. The main 


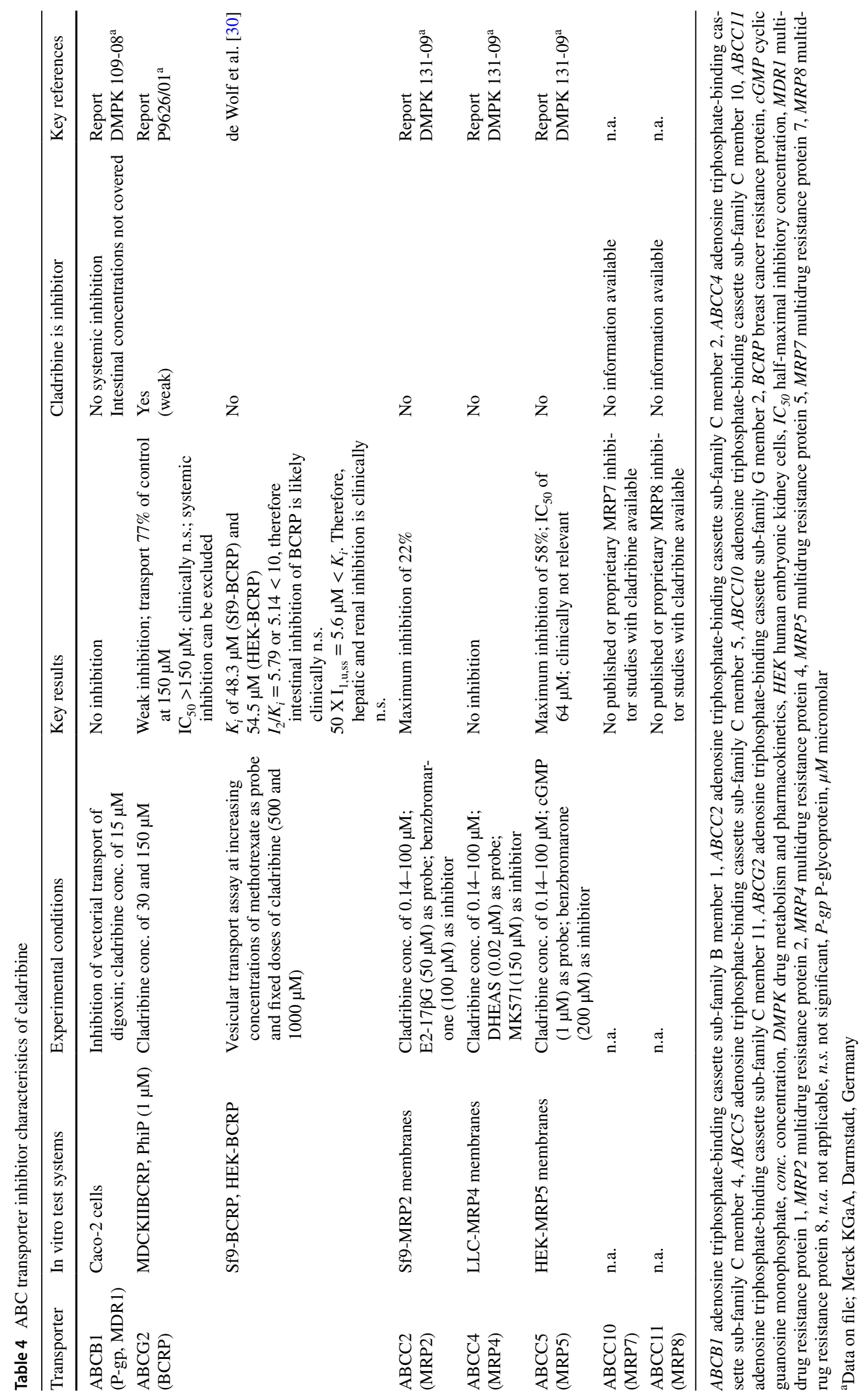




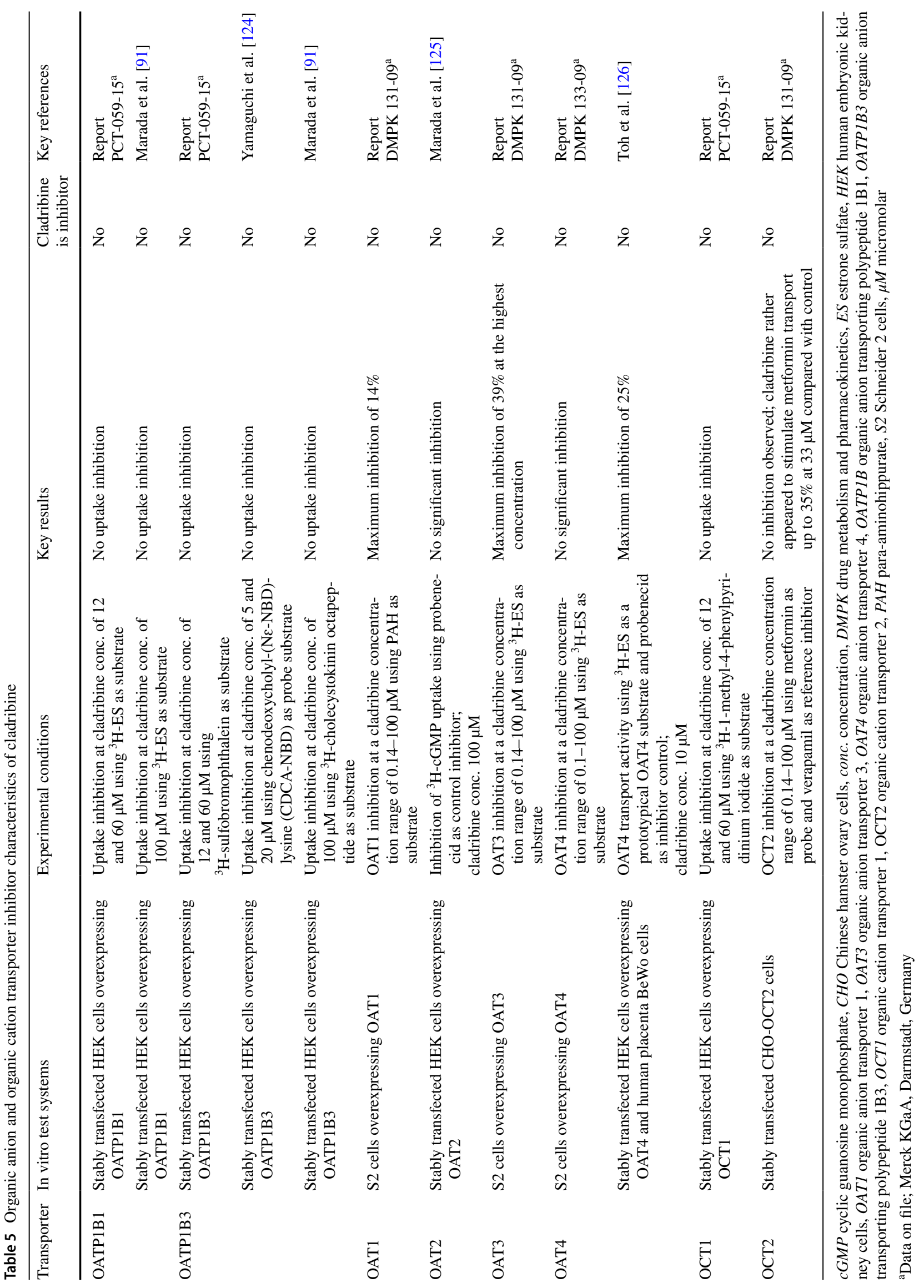




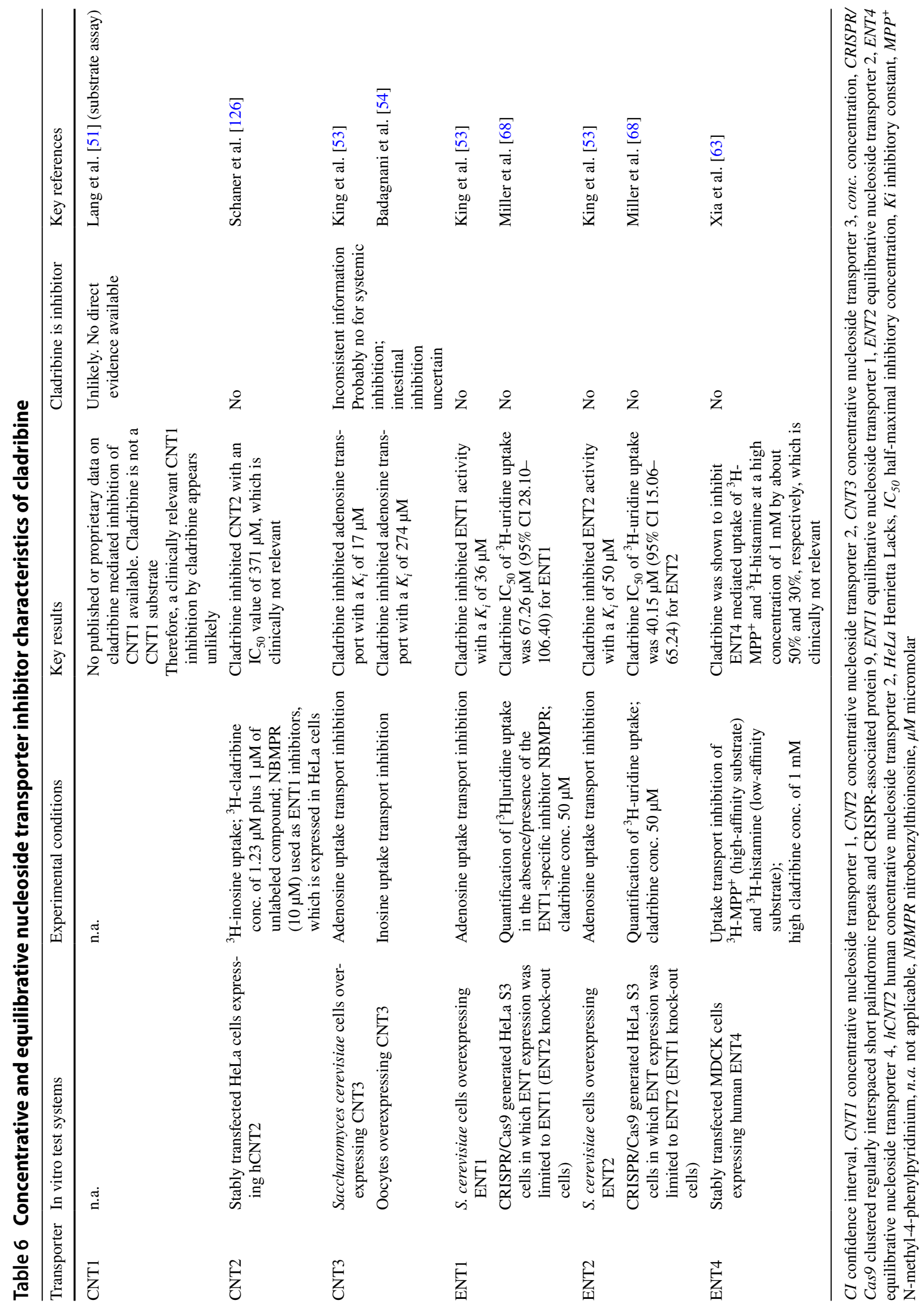


physiological role of BCRP is protection of cells against toxins and xenobiotics.

Expression of BCRP in lymphocytes and leukocytes is lower than expression of MRP1-5 and P-gp as assessed by qRT-PCR [24, 31]. BCRP expression in peripheral blood mononuclear cells (PBMCs) is about $10 \%$ of its expression in the intestine [32]. In human lymphocytes, expression decreases with age [25]. BCRP has been shown to transport purine and pyrimidine nucleoside analogs [30].

BCRP-mediated transport of cladribine has been tested in several cellular systems. Efficient vectorial cladribine transport was shown in Caco-2 cells with an efflux ratio (ER) range from 8.9 to 18 at concentrations of $5-50 \mu \mathrm{M}$. Cladribine ER decreased by about $50 \%$ in BCRP knock-down CPT-B1 cells (a novel and proprietary cell line derived from wild-type Caco-2 cells), with lower expression of BCRP and further to below 2 by exposure to the potent BCRP inhibitor fumitremorgin $C(10 \mu \mathrm{M})$, indicating that BCRP is responsible for vectorial transport in Caco-2 cells [data on file, Study Report DMPK 58-09; Merck KGaA].

In a recent study using a human BCRP-transfected MDCK cell line (BCRP-MDCKI) together with $1 \mu \mathrm{M}$ of PSC833, a specific P-gp inhibitor, the BCRP-mediated ER of cladribine was determined with 118 , which is about 6-fold to 13 -fold of the ER observed in Caco-2 cells as detailed above [34]. Large quantitative differences in the assessment of transporter-mediated ERs in different cell systems are likely due to differences in the respective transporter abundances [34].

In MDCKII-BCRP cells, ${ }^{3} \mathrm{H}$-cladribine was transported with a $K_{\text {m,app }}$ of $80 \mu \mathrm{M}$ [30], and BCRP overexpression reduced the accumulation of ${ }^{3} \mathrm{H}$-cladribine and cytotoxicity of cladribine in primary osteogenic sarcoma (Saos) cells [35]. Interestingly, BCRP-mediated transport was not observed in a vesicular transport assay and it was suggested that cladribine (a moderate-permeability drug) may have leaked out of vesicles by either passive diffusion or facilitation by ENTs [30]. However, the latter would be only applicable to the free cladribine pro-drug as nucleoside transporters (NTs) do not transport nucleotides, i.e., the active intracellular cladribine phosphate metabolites [36]. In conclusion, cladribine is efficiently transported by BCRP and the transport modulates the apparent permeability of the compound in various monolayer assays.

\subsubsection{MRP/ABCC Family Transporters}

MRPs belong to the subfamily $\mathrm{C}$ in the $\mathrm{ABC}$ transporter superfamily. Currently, nine MRPs are known to share a similar ATP-driven transport mechanism [37]. A wide range of endobiotics and xenobiotics can be transported by MRPs and different MRPs may have overlapping substrate specificity. MRPs are known to transport nucleoside analogs and their metabolites, specifically MRP4, MRP5, MRP7, and MRP8 [38, 39]. MRPs possess a broad expression profile; MRP2 is mainly expressed apically, while localization of MRP1, MRP4, and MRP5 is barrier dependent.

Transport of cladribine by several MRPs has been tested. Cladribine was not transported by MRP2 in a monolayer assay in MDCKII-MRP2 cells at concentrations of 0.05 , 0.1 , and $1.0 \mu \mathrm{M}$ (data on file, Study Report DMPK 134-09; Merck KGaA). These data are consistent with data from another study using a similar system [30].

Cladribine was also not transported by MRP4 as shown in a cellular uptake assay using the human embryonic kidney 293 (HEK293)-MRP4 cell line at concentrations of 0.05, 0.1 , and $1.0 \mu \mathrm{M}$, covering a concentration range of 20 -fold (data on file, Study Report DMPK 134-09; Merck KGaA). These data are consistent with data from two other studies using a MDCKII-MRP4 cell line [30]. In turn, a low-level resistance to cladribine (i.e., resistance factor of 1.7-2.2; the $\mathrm{IC}_{50}$ in the transfected cell line divided by that in the parental cell line) was observed in HEK293-MRP4 cells [40]. However, because of the lack of specific MRP4 inhibitors, it could not be shown that MRP4 inhibition could revert the observed low-level resistance. In another cell line, overexpression of MRP4 did not produce resistance to cladribine [41]. Thus, a role of MRP4 in cytotoxicity-related efflux of cladribine, as suggested by the HEK293-MRP4 cell study, appears unlikely. In conclusion, the majority of available in vitro evidence supports the notion that cladribine is not an MRP4 substrate.

Similar to MRP4, MRP5 was found not to transport cladribine in an MDCKII-MRP5 monolayer assay (data on file, Study Report DMPK 134-09; Merck KGaA). Although a resistance factor of 1.5 was observed in HEK293-MRP5 cells, a reversal of resistance upon MRP5 inhibition has not been shown [40]. Taken together, MRP2, MRP4, and MRP5 do not seem to play a meaningful role in transcellular efflux of cladribine. No studies are available on MRP7-mediated and MRP8-mediated transport of cladribine.

\subsection{SLC Family Efflux Transporters}

\subsubsection{MATES}

MATE proteins are apically expressed membrane transporters typically mediating the excretion of organic cations and zwitterions into bile and urine and thereby contributing to the hepatic and renal elimination of many xenobiotics [42]. Human MATEs include three major functional solute carriers: MATE1, MATE2, and the splice variant, MATE2K. The three functional isoforms are expressed abundantly in the apical membrane of renal proximal tubule cells and play roles in the secretion of cations and zwitterions into urine [43]. They function as cation/ $\mathrm{H}^{+}$antiporters in functional 
interplay with organic cation transporters (e.g., OCT2) localized at the basolateral membrane of proximal tubule cells [43, 44]. Current evidence for a role of MATEs in drug disposition and interactions is strongest for MATE1 and MATE2K [43].

Apart from its excretory function in the brush-border membrane of renal proximal tubule cells, MATE1 also plays an important role in biliary excretion of endobiotics and xenobiotics via the canalicular membrane of hepatocytes. Expression of MATE2K, in turn, is specific for the brush-border membrane of renal proximal tubule cells. The nucleoside reverse transcriptase inhibitors lamivudine and emtricitabine were shown to be substrates of MATE1 (both compounds) and MATE2K (lamivudine) [45, 46]. Thus, MATEs may be apical candidate transporters in functional interplay with (a) putative basolateral uptake transporter(s) in the renal secretion of cladribine. Unfortunately, no published data are available on whether cladribine may be a substrate to any of the MATE transporters. However, as cladribine was shown not to be an OCT2 substrate (see below), it may be considered unlikely that cladribine would be a substrate of MATEs as typical OCT2 cooperation transporters.

\subsection{Influx/Uptake Transporters: NTs}

Nucleoside transport in humans is mediated by members of two unrelated protein families, the SLC28 family of cationlinked CNTs and the SLC29 family of energy-independent ENTs. These families contain three and four members, respectively. Together, they play key roles in nucleoside and nucleobase uptake for salvage pathways of nucleotide synthesis. Moreover, they facilitate cellular uptake of several nucleoside and nucleobase drugs. [47]

\subsubsection{CNT/SLC28 Family}

Human CNTs are inwardly directed $\mathrm{Na}^{+}$-dependent NTs with high substrate affinity $\left(K_{\mathrm{m}} 1-50 \mu \mathrm{M} ; K_{\mathrm{m}}=\right.$ measure of the affinity of the substrate for the enzyme) found predominantly in intestinal and renal epithelial and other specialized cell types [48, 49]. Three CNTs (CNT1-3) mediate $\mathrm{Na}^{+}$-dependent co-transport of nucleosides and nucleoside analogs with CNT3 also mediating proton-driven co-transport [47]. At least one of the CNTs is localized in all major barrier-forming cell types but their localization and expression levels varies [47]. CNT1 primarily transports pyrimidine nucleosides, CNT2 primarily transports purine nucleosides, and CNT3 transports both pyrimidine and purine nucleosides [47].

In oocytes expressing CNT1, cladribine generated a small but significant current [50], but no transport was detected in stable transfectants containing CNT1 (known as TLCT1 cells) [51]. In contrast, CNT2 has been shown to transport cladribine both in oocytes expressing CNT2 [52] and Ara/ D2 transfectants albeit at a low rate of $0.023 \mathrm{pM} / \mu \mathrm{L}$ cell water/s [51]. The estimated $K_{\mathrm{m}}$ value for cladribine in this study was $187 \pm 20.3 \mu \mathrm{M}$, characterizing cladribine as a low-affinity substrate of CNT2 [52]. In addition, cultured human leukemic cells overexpressing CNT2 were more sensitive to the cytotoxicity of cladribine [53]. In two separate studies, cladribine uptake was shown to be efficient in oocytes expressing CNT3 [54, 55]. Therefore, cladribine is considered to be an efficient substrate of human CNT3 and a low-affinity substrate of CNT2. These findings are consistent with the existing evidence that both CNT2 and CNT3 are generally known to transport purine nucleosides.

\subsubsection{ENT/SLC29 Family}

ENTs are low-affinity $\left(K_{\mathrm{m}} 50-700 \mu \mathrm{M}\right)$, high-capacity bidirectional NTs that are widely distributed in human tissues [56], i.e., ENTs are ubiquitously found in most, possibly all, cell types [47]. There are three human ENT isoforms known (ENT1, ENT2, and ENT3), which display a broad substrate specificity and mediate bidirectional fluxes of purine and pyrimidine nucleosides down their concentration gradients [56]. ENT2 and, to a lesser extent ENT1, additionally transport nucleobases [56]. ENT1 and ENT2 are primarily located at the plasma membrane, although it has been shown recently that ENT2 also resides in submembrane regions from where it can be rapidly translocated to the plasma membrane [57]. In addition, ENT1 and ENT2 can form hetero-oligomers and homo-oligomers at the plasma membrane and in the submembrane region [57]. Changes in the localization and oligomeric status of ENT1 and ENT2 can rapidly modify the uptake profile of nucleosides and nucleobases.

In contrast, ENT3 functions predominantly intracellularly, where it is expressed in lysosomal [56] and mitochondrial [58] membranes. Thus, ENT3 is not relevant for the discussion of transporter-based absorption or distribution interactions of cladribine and will not be considered further herein.

In addition, an evolutionarily divergent ENT transporter (ENT4) was identified. Substrate specificity of ENT4 is somewhat different as it transports monoamines and thus was also denoted plasma membrane monoamine transporter because of its ability to transport organic cations including biogenic amines, cationic therapeutics, and neurotoxins [36]. ENT4 has been also shown to transport adenosine [59], and more recently 2-chloro-adenosine in a pH-dependent manner [60]. ENT4 is most abundantly expressed in the brain, where it may play a role in the clearance of monoamine neurotransmitters [61, 62]. In addition to the brain, messenger RNA (mRNA) transcripts of ENT4 are also found in several other organs, including the kidney, where it is expressed on the apical membranes of renal epithelial cells 
and may be involved in urinary organic cation reabsorption $[61,63]$.

ENT1 and ENT2 are the best characterized ENTs and have been shown to be expressed in all major barriers [47] and in immune cells [64]. Overall, ENT1 and ENT2 are the major contributors to nucleoside transport across the plasma membrane in many tissues $[56,65]$.

ENT1 efficiently transports cladribine in cultured human leukemic cells with a $K_{\mathrm{m}}$ of $23 \mu \mathrm{M}$ and overexpression of ENT1 leads to a significant increase in the cytotoxicity of cladribine $(10 \mu \mathrm{M})$ compared with control cells [53]. Cytotoxicity of cladribine to cultured leukemic lymphoblasts was enhanced three-fold in the presence of the ENT1-specific/ selective inhibitor nitrobenzylthioinosine (NBMPR) when cells were preloaded with cladribine, suggesting that ENT1 also plays an important role in the efflux of cladribine from lymphocytes [66].

ENT2-mediated (i.e., NBMPR-insensitive) transport has been shown for cladribine [67], although in contrast to the expression of ENT1 and CNT2, the expression of ENT2 in cultured human leukemic cells did not result in increased cytotoxicity over control cells [53]. Recently, however, ENT2-mediated transport of cladribine has been confirmed by CRISPR/Cas9-generated HeLa cell lines in which ENT expression was limited to ENT1 or ENT2 [68].

Taken together, there is robust information that cladribine is a substrate of ENT1, and data from two different in vitro systems showing that cladribine is also transported by ENT2. Evidence of ENT4-mediated transport of adenosine [59] and 2-chloro-adenosine [60] suggests that ENT4 may be considered a reasonable candidate transporter for cladribine. As shown recently, JN-desmoplastic small round cell tumor 1 cells abundantly expressing ENT4 mRNA were more sensitive to the $\mathrm{pH}$-dependent cytotoxic effect of cladribine than cells with lower ENT4 expression. A decreasing level of ENT4 with Wilms' tumor 1-2 small interfering RNA resulted in markedly reduced cladribine cytotoxicity, highlighting a potential role of ENT4 in the cellular uptake and cytotoxicity of cladribine $[69,70]$.

\subsubsection{OATP}

OATP1B1 and OATP1B3 are key liver uptake transporters specifically expressed on the basolateral (i.e., sinusoidal) membrane of human hepatocytes, playing an important role in the hepatic uptake of various endogenous substrates and drugs [71, 72]. Nucleosides and nucleoside analogs are not among the typical substrates of OATP1B1 and OATP1B3, although it was shown recently that OATP1B 1 transports cytarabine [73].

No data are available on potential OATP1B1-mediated and OATP1B3-mediated transport of cladribine. However, because no active uptake of cladribine into hepatocytes has been demonstrated (data on file, Study Report 15-GR028P0; Merck KGaA), and cladribine did not inhibit OATP1B1mediated and OATP1B3-mediated uptake of test substrates, it is not considered to be acting as a competitive inhibitor/ substrate of these transporters (data on file, Study Report PCT-059-15; Merck KGaA). Taken together, it appears unlikely that cladribine may be a substrate of liver-specific OATPs.

\subsubsection{OCTs}

There are three main isoforms of OCTs (OCT1, OCT2, and OCT3). OCTs are critically involved in intestinal absorption, hepatic uptake, and renal excretion of hydrophilic drugs. In excretory organs, OCTs frequently function in cooperation with MATE proteins to mediate transepithelial transport of organic cations [74].

OCT1 is widely expressed with a particularly high expression at the sinusoidal membrane of hepatocytes [75]. OCT1 has a broad substrate specificity and functions in hepatic uptake and thus is a significant contributor to hepatic clearance of drugs [76]. OCT1 is known to transport nucleoside analogs [77]. No data are available on OCT1-mediated transport of cladribine. However, because no active uptake of cladribine into hepatocytes has been demonstrated (data on file, Study Report 15-GR028-P0; Merck KGaA) and cladribine did not inhibit OCT1 (data on file, Study Report PCT059-15; Merck KGaA), it appears unlikely that cladribine may be a substrate of OCT1.

OCT2 is considered to be a kidney-specific basolateral transporter responsible for the uptake of substrates into renal proximal tubule cells. However, OCT2 has been shown by qRT-PCR also to be expressed in $\mathrm{CD}^{+}$cells isolated from human immunodeficiency virus-infected patients, and OCT2 was shown to transport the nucleoside reverse transcriptase inhibitor lamivudine [78]. OCT2, however, does not transport cladribine (data on file, Study Report DMPK 21-10; Merck KGaA).

OCT3 has a very broad tissue expression pattern and transports a wide range of monoamine neurotransmitters, hormones, and steroids. Its broad substrate profile overlaps with those of OCT1, OCT2, as well as MATE1 and MATE2K. No data are available on potential OCT3-mediated transport of cladribine.

\subsubsection{OATs}

To date, seven human OATs have been identified and functionally characterized (OAT1; OAT2; OAT3; OAT4; OAT7; OAT10; and URAT1) [79-81]. Compared with OATPs, OATs transport smaller and more hydrophilic organic anions. They mediate the transport of a diverse range of 
low-molecular-weight substrates including steroid hormone conjugates, biogenic amines, various drugs, and toxins [82]. OAT1 and OAT3 mediate the basolateral cellular entry step in the renal secretion of many organic anions [71].

OAT1 is expressed at the basolateral membrane of renal proximal tubule cells $[83,84]$ and at the plasma membrane of skeletal muscle cells [85]. OAT1 has been shown to be below the limit of quantitation by qRT-PCR in peripheral leukocytes [31] and weak expression was demonstrated by a microarray study in leukocytes, neutrophils, and mononuclear cells [93]. OAT1 has been shown to transport nucleoside analogs and phosphonates [86, 87]. However, OAT1 does not transport cladribine (data on file, Study Report DMPK 21-10; Merck KGaA).

OAT2 has been identified at the basolateral membrane of proximal renal tubules [88], and it is assumed to be expressed at the basolateral membrane of human hepatocytes based on findings in rodents [82]. Compared to other OAT family members, OAT2 has only recently been recognized as an important drug transporter because of its expression in both the liver and kidney, and its ability to transport not only a wide variety of xenobiotics but also numerous physiologically important endogenous compounds, including creatinine. OAT2 has been shown to transport the synthetic nucleoside analogs acyclovir and ganciclovir [89] and the nucleobase 5-fluorouracil [90]. Although no data are available on potential OAT2-mediated transport of cladribine, Marada and colleagues demonstrated the absence of OAT2 inhibition by cladribine. Based on this, cladribine is not considered to act as a competitive inhibitor/substrate of OAT2 [91].

The OAT3 protein is localized at the basolateral membrane of proximal renal tubules [92], and is thought to be a kidney-specific transporter. OAT3 has been shown to be below the limit of quantitation by qRT-PCR in peripheral leukocytes [31] and weak expression was demonstrated by a microarray study in leukocytes, neutrophils, and mononuclear cells [93]. OAT3 prefers larger amphiphilic compounds and is less known to transport nucleoside analogs. Consistent with this substrate profile, no OAT3-mediated cladribine transport was detected in transfected S2 cells overexpressing OAT3 (data on file, Study Report DMPK 21-10; Merck $\mathrm{KGaA})$.

OAT4 protein expression has been identified at the apical membrane of renal proximal tubule cells $[94,95]$ and at the basolateral membrane of syncytiotrophoblasts in the placenta [96]. Thus, in the absence of pregnancy, OAT4 is thought to be a kidney-specific apical transporter as the kidney is the only organ where it was shown to be expressed to any significant extent by a microarray study [95].

OAT4 is an anion exchanger. By using different counterions, it works in a secretory or in a re-absorptive manner. The only nucleoside analog reported as a low-affinity $\left(K_{\mathrm{m}}\right.$
$=151.8 \mu \mathrm{M})$ OAT4 substrate is azidothymidine/zidovudine [97]. No OAT4-mediated cladribine transport was detected in transfected S2 cells overexpressing OAT4 (data on file, Study Report DMPK 21-10; Merck KGaA). The roles of OAT5, OAT7, OAT10, and URAT1 for drug transport and possible interactions are less well characterized [82], and no data are currently available concerning their possible involvement in cladribine transport.

\subsection{Summary of the Transporter Substrate Characteristics of Cladribine}

The available evidence as detailed above suggests that distribution of cladribine across biological membranes is facilitated by a number of efflux and uptake transporters. Among the key ABC efflux transporters, only BCRP appears to be an important transporter of cladribine, while P-gp does not appear to transport cladribine in an efficient manner, and thus may only play an ancillary role in cladribine efflux at biological barriers with high P-gp expression [5, 20, 30]. Cladribine is not a substrate of MRP2, MRP4, or MRP5 (Table 1).

Intracellular uptake of cladribine appears to be exclusively mediated by ENTs and CNTs, specifically by ENT1, ENT2, ENT4, CNT2 (low affinity), and CNT3 (Table 2). There is no evidence that SLC uptake transporters, such as OATPs, OATs, and OCTs, are involved in the transport of cladribine (Table 3).

\subsection{Cladribine Transport and Transporter Interplay at Major Biological Barriers}

The main functions and interplay of transporters that have been shown to play a role in the active transport of cladribine will be briefly discussed for key biological barriers.

\subsubsection{Intestinal Epithelial Cells}

Figure 1a illustrates transporters involved in the uptake and efflux of cladribine in the small intestine. Intestinal epithelial cells express a variety of NTs shown to transport cladribine such as CNT2 and CNT3 in the apical (luminal) membrane as well as ENT1 and ENT2 mainly in the basolateral (i.e., at the blood side) surface, together working in concert to facilitate the absorption of nucleosides and nucleoside analog drugs [47]. CNT2 has been suggested as the main contributor to the intestinal absorption of purine nucleosides [98], and CNT3 transports both pyrimidine and purine nucleosides [47]. As cladribine was shown to be a substrate of CNT3 and CNT2 (low affinity), it is reasonable to assume that these transporters facilitate intestinal absorption of cladribine in collaboration with basolateral-expressed ENT1 and ENT2. More recently, apical localization of ENT1 was 
a Intestinal Epithelial Cells

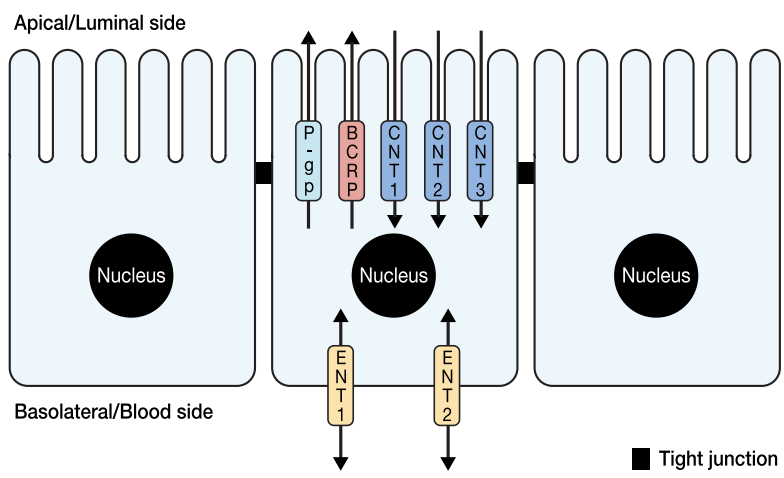

Renal Proximal Tubule Cells

C

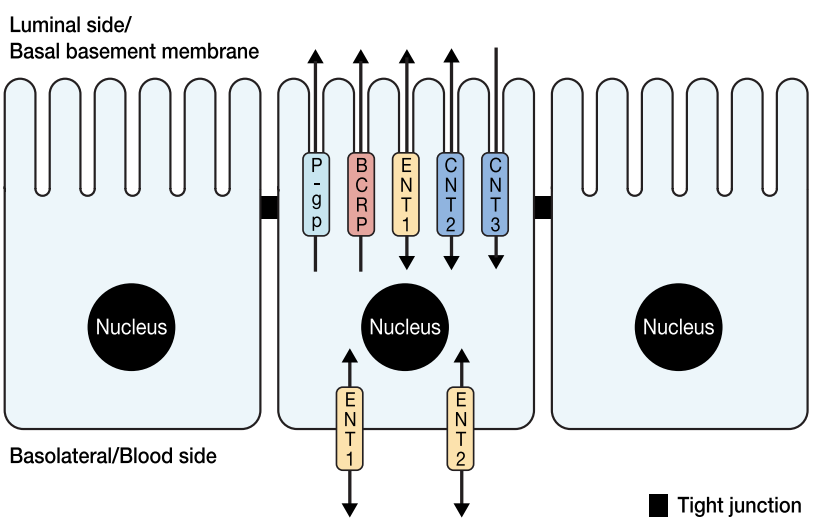

e

Choroid Plexus Epithelial Cells of the Blood Cerebrospinal Fluid Barrier

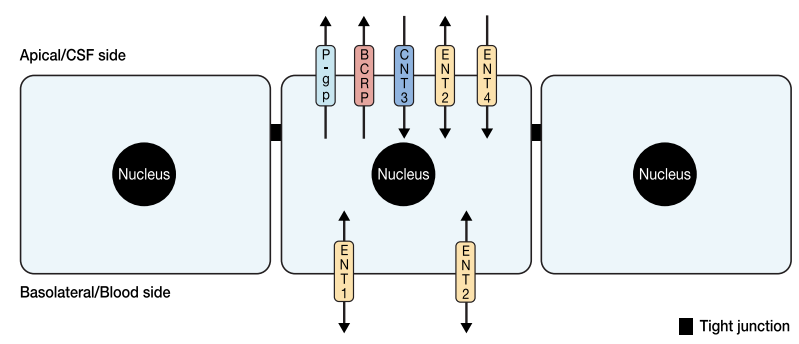

b

Hepatocytes

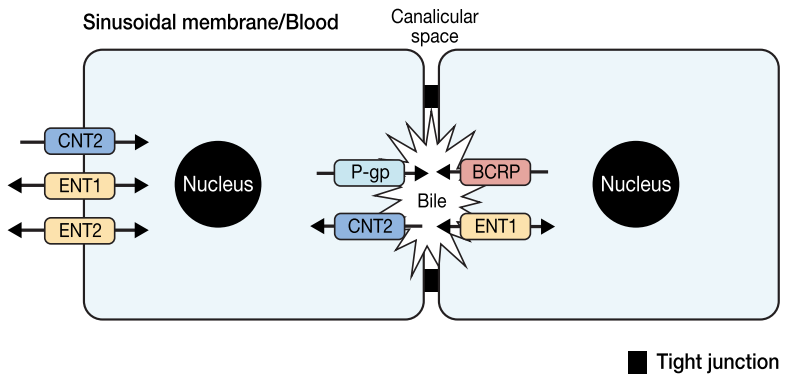

d

Microvascular Endothelial Cells of the Blood Brain Barrier

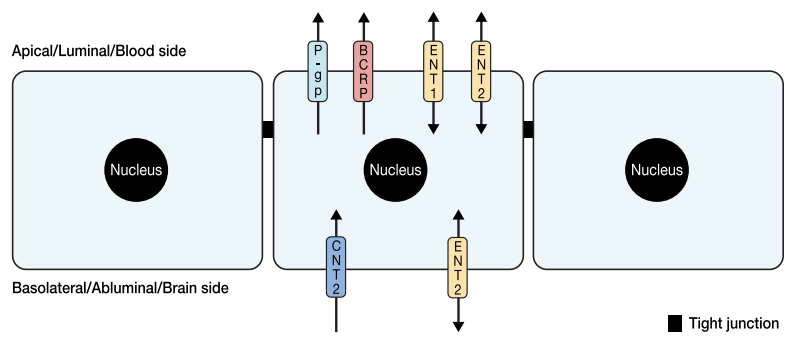

f

Lymphocyte

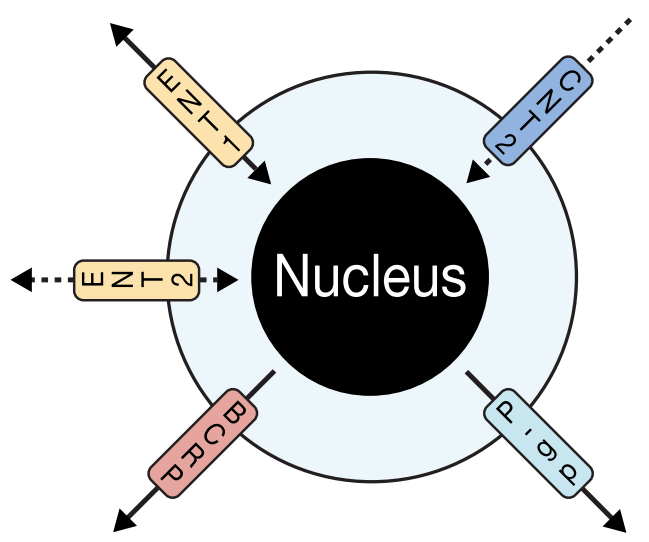

(CSFB), and $\mathbf{f}$ lymphocytes. BCRP breast cancer resistance protein, $C N T$ concentrative nucleoside transporter, ENT equilibrative nucleoside transporter, $P$ - $g p$ P-glycoprotein. The dotted line indicates a minimal contribution

was lower than the basolateral expression of ENT2 [99]. Taken together, both CNTs and ENTs are likely to be working in concert in the intestinal absorption of nucleosides and [99]. Based on the staining, the apical expression of ENT2 
nucleoside analog drugs including cladribine. However, the absorption of cladribine is unlikely to be entirely dependent on active NT-mediated transport, but may occur to some extent by passive diffusion (see Sect. 1.2).

The oral bioavailability of cladribine is reported as $45.6 \%$ [20]. Therefore, and also because cladribine is not subject to any cytochrome P450 subfamily 3A (CYP3A)-based firstpass metabolism, it is conceivable to consider the role of apical efflux transporters as limiting factors to the oral bioavailability of cladribine [100]. This assumption is further supported by the low non-renal clearance of cladribine (23.4 $\mathrm{L} / \mathrm{h}$ ) and in turn much lower hepatic clearance, compared to the hepatic blood flow (about $1500 \mathrm{~L} / \mathrm{min}$ ).

Of the three major apical efflux transporters in the intestine, MRP2 does not transport cladribine. The intestinal protein abundance of P-gp, relative to the total intestinal transporter abundance, has been reported to range between 11 and $14 \%$ in the jejunum, and was found to be about $19 \%$ in the ileum. In the same study, BCRP abundance in the entire small intestine was found to range between 4 and $8 \%$ [101]. Thus, in quantitative terms, the intestinal P-gp expression exceeds BCRP expression by about two-fold, which may compensate to some extent for the low cladribine transport efficiency shown for P-gp. However, BCRP is by far a more efficient transporter of cladribine than P-gp as evidenced by several in vitro studies. For instance, when cladribine transport was examined within the same study in MDCKII-based transfectants, BCRP was more efficient than P-gp [30]. In a more recent study using a cell line with reduced potential for interference by P-gp (CPT-P1), several potent, relatively specific BCRP inhibitors almost completely inhibited cladribine efflux, whereas several BCRP substrates and less specific inhibitors of efflux showed different degrees of inhibition [102]. Thus, taken together, BCRP is considered the key contributor for the limitation of cladribine absorption by intestinal efflux.

\subsubsection{Hepatic Uptake and Excretion}

Cladribine has been shown not to be a substrate or inhibitor of key hepatic uptake transporters including OATP1B1, OATP1B3, OCT1, OCT3, OAT2, and OAT7, although data for OAT7 are lacking. However, CNTs and ENTs are expressed in the human liver, and have been shown to play a role in the hepatic uptake of nucleoside analog drugs [58]. In hepatic tissue, the rank order of mRNA expression of the transporters was $\mathrm{CNT} 1 \sim \mathrm{ENT} 1>\mathrm{ENT} 2 \sim \mathrm{CNT} 2>\mathrm{CNT} 3$ [58]. In sandwich-cultured hepatocytes, the mRNA expression of CNT2 and ENT2 was comparable to that in hepatic tissue, whereas the expression of corresponding transporters in the two-dimensional hepatocyte cultures was lower. Colocalization studies demonstrated predominant localization of these transporters at the sinusoidal membrane and ENT1,
CNT1, and CNT2 also at the canalicular membrane. Unlike CNT1 and ENT1, only moderate levels of ENT2 ( 100-fold $<$ ENT1) and CNT2 $(\sim 100$-fold $<$ CNT1) transcripts and a low level of CNT3 transcripts were expressed in the human liver. Functional data suggest that the transport of both purine and pyrimidine nucleosides into sandwich-cultured hepatocytes is predominantly mediated by ENT1 followed by ENT2 $\sim \mathrm{CNT} 2$ for guanosine and ENT2 $\sim \mathrm{CNT} 1$ for thymidine [58].

Figure $1 \mathrm{~b}$ shows transporters possibly involved in the uptake and efflux of cladribine in the liver. On the sinusoidal membrane of human hepatocytes, ENT1 and ENT2 were identified as significant contributors to the total transport of nucleosides into hepatocytes, whereas the contribution of CNTs was substrate dependent [58]. Considering the uptake transporter substrate characteristics of cladribine together with the expression pattern of uptake transporters at the sinusoidal membrane (i.e., at the blood side) of hepatocytes [43], ENT1 and ENT2 are the only conceivable candidate transporters for hepatic uptake of cladribine, as CNT3 only shows low-level expression in human hepatocytes [58]. This means that any transporter-mediated hepatic uptake of cladribine would be almost entirely ENT1 and ENT2 dependent, possibly with some ancillary contributions of CNT2. However, results of an in vitro uptake study of ${ }^{14} \mathrm{C}$-labeled cladribine into cryopreserved human hepatocytes indicated that cladribine uptake was low, with a range from $7.5 \pm 1.0$ to $15 \pm 6 \mu \mathrm{L} / 10^{6}$ cells, when compared with positive controls for OCT1 $\left(69 \mu \mathrm{L} / 10^{6}\right.$ cells $)$ and OATP1B 1/3-mediated $(24$ $\mu \mathrm{L} / 10^{6}$ cells) uptake, respectively. In this study, cladribine uptake was neither concentration nor time dependent, saturation was not achieved at the concentrations tested (up to $251 \mu \mathrm{M}$ ), and uptake was not inhibited in the presence of a mix of multiple transporter inhibitors (rifampicin $[20 \mu \mathrm{M}]$, cyclosporin $\mathrm{A}[20 \mu \mathrm{M}]$, and quinidine $[100 \mu \mathrm{M}]$ ), although the inhibitors employed in this study are not known as potent ENT1 inhibitors (data on file, Study Report 15-GR028-P0; Merck KGaA). However, recently, it was shown that the expression of many plasma membrane proteins was lower in freshly isolated human hepatocytes than in liver tissue. This included transport proteins that determine hepatocyte exposure to many drugs and endogenous compounds, although ENTs/CNTs were not specifically examined in this study [103]. In this context, it is important to note that the cladribine hepatic uptake study was conducted in suspended hepatocytes that were cryopreserved twice before being used. While a decline in hepatic enzyme activities in response to the cryopreservation process is known, adverse effects of transporter functions in double-cryopreserved hepatocytes have not yet been examined. Provided that these observations may be transferable to transporter activities, ENT-mediated cladribine uptake in the test system may not have been well captured (personal information, Brian 
Ogilvie, Sekisui XenoTech, LLC). Taken together, the role of ENT1-mediated and ENT2-mediated hepatic uptake of cladribine in vivo remains unknown. However, clinical DDIs with hepatic ENTs have not been demonstrated to date. In the absence of a significant hepatic metabolism of cladribine (e.g., by CYP enzymes) [20], the possible role of efflux transporters (e.g. BCRP, P-gp, and ENT1) in the biliary excretion of cladribine or any metabolites will not be considered further herein.

\subsubsection{Renal Uptake and Excretion}

Renal elimination is an important clearance pathway of cladribine. A population pharmacokinetic analysis showed that renal and non-renal routes of cladribine elimination are approximately of similar quantitative importance, with median values of $22.2 \mathrm{~L} / \mathrm{h}$ and $23.4 \mathrm{~L} / \mathrm{h}$ for renal and nonrenal clearance, respectively [104]. Renal clearance appears to exceed the glomerular filtration rate, indicating net tubular excretion of cladribine in addition to glomerular filtration [20]. Figure 1c shows transporters possibly involved in the uptake, efflux, and reabsorption of cladribine in the kidney. As cladribine was shown not to be a substrate of the kidneyspecific basolateral (i.e., blood side) uptake transporters OCT2, OAT1, and OAT3, nor of the kidney-specific apical (i.e., urinary side) transporter OAT4, only BCRP, ENT1, and possibly P-gp remain as conceivable candidate transporters for active tubular secretion of cladribine (Fig. 1c).

NTs in the kidney mediate renal reabsorption and secretion of nucleosides [105]. All five NTs are expressed in the kidney. CNTs primarily localize to the apical membrane (i.e., urinary side) of renal epithelial cells while ENTs primarily localize to the basolateral membrane (i.e., blood side). This implies that these transporters work in concert to primarily mediate tubular reabsorption of naturally occurring nucleosides and nucleoside analogs [106]. In addition, ENT1 is also expressed at apical membranes of renal epithelia, and thus may participate in both selective secretion and reabsorption of nucleosides and nucleoside analog drugs, including cladribine $[105,106]$. Because of their bidirectional functionality, basolateral (i.e., blood side) located ENT1 and ENT2 are the most likely candidate transporters facilitating uptake of cladribine from the blood into renal proximal tubule cells, as none of the other basolateral uptake candidates tested were actually shown to facilitate cladribine uptake. Therefore, it is likely that ENT1 and ENT2 facilitate transmembrane transport of cladribine through the basolateral membrane (i.e., blood side), while ENT1 may also be involved in the apical urinary excretion of cladribine.

In the apical membrane (i.e., luminal side) of renal proximal tubule cells, of the three transporters (i.e., ENT1, BCRP, and P-gp) possibly implicated in renal efflux of cladribine into urine, only BCRP and ENT1 have been shown to transport cladribine efficiently. In vitro, P-gp-mediated transport of cladribine does not seem to be efficient. However, P-gp expression in the kidney at the mRNA level was higher than BCRP expression [107, 108]. It is known that mRNA data in transporter research need to be interpreted with caution as they do not always correlate with changes in the amount of functional transporter expressed. More recent proteomics data on kidney cortex cells indicated that P-gp generally showed the highest abundance among all apical efflux transporters, with P-gp expression exceeding that of BCRP by about 40 -fold to 150 -fold when $\mathrm{pM} / \mathrm{mg}$ protein data are considered [107, 109-112]. However, one study that quantified P-gp and BCRP expression by qPCR in conditionally immortalized proximal tubule cells showed comparable expression levels of P-gp and BCRP [107]. Finally, Huls and colleagues found, by using immunohistochemical analysis, a clear localization of BCRP to the proximal tubule brush border membrane of the human kidney comparable to that of other ABC transporters such as P-gp, MRP2, and MRP4 [112-114]. This study showed, that in addition to other apical ABC transporters, BCRP may be important in renal drug excretion. Based on this, although it is acknowledged that literature data on renal BCRP expression are largely inconsistent, BCRP is considered likely to be an important contributor of active renal tubular secretion of cladribine. Taken together, active tubular secretion of cladribine appears to be most likely driven by BCRP, ENT1, and P-gp. Regarding the latter, the very high P-gp expression in renal proximal tubule cells may compensate for the low P-gp transport efficiency of cladribine.

\subsubsection{BBB and Blood Cerebrospinal Fluid Barrier (BCSFB)}

The brain capillary endothelial cells form the BBB, which separates the blood and the brain interstitial fluid. The CP is a vascularized tissue that is located in each ventricle of the brain. CP ependymal cells are the main site of ventricular secretion of the cerebrospinal fluid (CSF) and, along with the arachnoid membrane, form the BCSFB. Both BBB and BCSFB form physically tight barriers by the expression of tight junctions and transporter proteins, which prevent the passage of molecules from the central circulation into the brain interstitial fluid and from the brain circulation into the CSF. Efflux transporters expressed at the luminal membrane of the BBB are capable of effluxing a multitude of chemically diverse compounds, including toxins and xenobiotics, often in cooperation with transporters expressed at the abluminal membrane, from the brain into blood.

Some quantitative proteomic studies on drug transporters abundance at the BBB have been conducted [115-117]. Transporters involved in the uptake and efflux of cladribine across the BBB and the BCSFB are illustrated in Fig. 1d and $\mathrm{e}$, respectively. The figures show that the transport processes 
at the BCSFB barrier functionally differs from those at the BBB. For example, P-gp and BCRP at the BBB act as apical (i.e., blood side) efflux transporters thereby limiting entry of substrates into the brain (Fig. 1d), while both transporters secrete substrates from the brain circulation into the CSF at the BCSFB (Fig. 1e).

Among the three major $\mathrm{ABC}$ efflux transporters expressed at the human BBB (i.e., P-gp, BCRP, and MRP4), only $\mathrm{BCRP}$ and to some extent P-gp are considered contributors to cladribine efflux. In a quantitative proteomics study of membrane transporters in human brain microvessels, BCRP showed the most abundant protein expression $(8.14 \mathrm{fmol} /$ $\mu \mathrm{g}$ protein) closely followed by P-gp ( $6.06 \mathrm{fmol} / \mu \mathrm{g}$ protein) [117]. As P-gp is not considered to transport cladribine efficiently, BCRP represents the only efficient BBB efflux transporter limiting the central nervous system uptake of cladribine. Available data indicate that cladribine can permeate the BBB and/or BCSFB interfaces to some extent as a CSF/plasma concentration ratio of approximately 0.25 was reported for cladribine [118]. This in part could be either due to passive permeability or more likely through ENT1mediated and ENT2-mediated apical uptake (i.e., blood side) in concert with ENT2-mediated basolateral efflux (i.e., central nervous system side) at the BBB. In particular, ENT1 is abundantly expressed in the human BBB as measured by quantitative targeted proteomics [116]. In addition, basolateral ENT1 and ENT2 in concert with apical ENT2, BCRP, and possibly P-gp in ependymal cells of the CP could also well contribute to the CSF concentrations of cladribine [47].

\subsubsection{Immune Cells}

B-lymphocyte and T-lymphocyte populations are known as the key pharmacological targets of cladribine in the treatment of MS. As lymphocytes make up the majority of the PBMC, PBMC data are also considered herein, while transporter expression of other immune cells (e.g., granulocytes, macrophages) will not be discussed. Transporters involved in the uptake and efflux of cladribine into lymphocytes are illustrated in Fig. 1f. ENT1, ENT2, and CNT2 are abundantly expressed in primary lymphocytes (i.e., PBMCs and $\mathrm{CD}^{+}{ }^{+} \mathrm{T}$-lymphocytes), with a preferential activity of ENT1. A significant upregulation in the expression of ENTs (100-fold) and activity (30-fold) was seen under phytohemagglutinin stimulation of primary T-lymphocytes [64]. ENT1 expression has also shown the greatest increase upon phytohemagglutinin stimulation in PBMCs as well as CD4 ${ }^{+}$T-lymphocytes in another qPCR study [93]. Overall, ENT1 was one of the highest expressed NTs in various classes of WBCs including PBMCs [119].

Functional studies quantifying uridine transport in nonstimulated PBMCs showed minimal contribution of ENT2 activity to nucleoside transport in primary lymphocytes. In addition, the CNT2 (i.e., $\mathrm{Na}^{+}$dependent) component of nucleoside transport appeared to be residual and near negligible [64].

CNT2 is the only CNT substantially expressed in PBMCs and $\mathrm{CD} 4^{+}$T-lymphocytes [64]. Therefore, ENT1 and ENT2 may be considered the key transporters in the uptake of cladribine into lymphocytes, possibly with an ancillary contribution of CNT2.

Among $\mathrm{ABC}$ efflux transporters, P-gp expression in human lymphocytes in a qPCR study was intermediate but displayed a significantly higher expression than BCRP [25]. Among lymphocytes, $\mathrm{CD} 8^{+} \mathrm{T}$-lymphocytes and natural killer cells express higher $\mathrm{P}$-gp levels than $\mathrm{CD} 4^{+} \mathrm{T}$-lymphocytes and B-lymphocytes [25, 26]. Therefore, BCRP, ENT1, and ENT2, along with P-gp, may play a role in efflux of cladribine from human lymphocytes. BCRP may play an additional role by effluxing one of the phosphorylated intracellular cladribine metabolites, i.e., cladribine-AMP [30], while ENTs are known for their inability to transport nucleotides (i.e., the phosphorylated intracellular cladribine metabolites) [36]. This implies that NTs do not play a role in the efflux of cladribine nucleotides from intracellular compartments (e.g., lymphocytes), while BCRP is capable to efflux the parent drug cladribine as well as the nucleotide 2-Cd-AMP, but not 2-Cd-ADP or 2-CD-ATP.

We are unaware of published data on the capability of other $\mathrm{ABC}$ transporters to efflux intracellular cladribine nucleotides. However, as P-gp does not transport cladribine efficiently, and cladribine is not a substrate of MRP transporters, it appears unlikely that these transporters may play a role in the efflux of active cladribine metabolites.

It is worthy to note that the apparent lack of engagement of MRP efflux transporters and the poor substrate characteristics of cladribine towards P-gp, together with a relatively low BCRP expression in lymphocytes [25] along with the inability of ENTs to efflux cladribine nucleotides may favor intracellular accumulation of cladribine and its active metabolites in its target cells. Of note, BCRP expression in PBMCs is only about $10 \%$ of its expression in the intestine [32], and BCRP expression in human lymphocytes has been reported to decrease with age [24]. Besides BCRP, ENT1 and ENT2 are thought to be contributors to the active efflux of cladribine parent drug from WBCs, besides their role as cladribine uptake transporters [66]. Taken together, cladribine uptake into lymphocytes is most likely mediated by ENT1 and ENT2, possibly with some contribution by CNT2 $[119,120]$. while the efflux of cladribine from lymphocytes is likely mediated by BCRP and ENT1, with contributions of ENT2 and P-gp. 


\subsection{Transporter Inhibitor Characteristics of Cladribine}

There is ample in vitro information available to support the prediction that cladribine does not inhibit the most important $A B C$ efflux transporters in vivo. In vitro inhibition studies were conducted for P-gp (in Caco-2 cells), BCRP (in MDCKII-BCRP cells), MRP2, MRP4, and MRP5 (in membrane vesicle preparations), OATP1B1 and OATP1B3 (in transfected HEK cells), OAT1 and OAT3 (in CHO cells) and OAT4 (in transfected $\mathrm{S} 2$ cells), and organic cation transporters, i.e., OCT1 (in transfected HEK cells) and OCT2 (in CHO cells) $[5,20]$.

\subsubsection{Efflux Transporters}

Cladribine at $15 \mu \mathrm{M}$ did not inhibit vectorial transport of digoxin in Caco-2 cells (data on file, Study Report DMPK 108-09; Merck KGaA). Thus, according to standard regulatory criteria, inhibition of P-gp by cladribine is not expected. Based on limitations of this P-gp interaction study (only one concentration employed that did not cover intestinal concentrations), no definite conclusions on the potential of cladribine to inhibit intestinal P-gp can be drawn. However, as cladribine tablets contain hydroxypropylbetadex, which may result in complex formation with other medicinal products, it is recommended in the cladribine label that administration of any other oral medicinal product must be separated from cladribine dosing by at least $3 \mathrm{~h}$ [5]. In following the label, no other drug should be orally administered within this time window, which renders transporter-based absorption interactions, competitive in nature and hence linked to the simultaneous presence of the competing substrates, a wholly academic question.

In vitro, cladribine has been characterized as a weak inhibitor of human BCRP with an $\mathrm{IC}_{50}$ value $>150 \mu \mathrm{M}$, i.e., ( 20\% inhibition at $150 \mu \mathrm{M})$ [data on file, Study Report P9626-01; Merck KGaA]. Literature data confirm cladribine as a modest in vitro inhibitor of BCRP with a $K_{i}$ value of around $50 \mu \mathrm{M}$ in a vesicular transport system [30]. Hence, potential in vivo inhibition of intestinal or systemic BCRP by cladribine can be excluded [5].

Of the other efflux transporters tested (MRP2, MRP4, and MRP5), only inhibition of MRP5 yielded an $\mathrm{IC}_{50}$ value $(64 \mu \mathrm{M})$ [data on file, Study Report DMPK 131-09; Merck $\mathrm{KGaA}]$. In the BBB endothelial cells, MRP5 is localized apically/luminally [121]. Based on reported expression levels, MRP5 is not considered a dominant efflux transporter at the BBB and even for the more important and highly expressed luminal efflux transporters such as BCRP and P-gp, the likelihood of clinical transporter-mediated DDIs has been debated [122]. For BBB efflux transporters, no specific instructions are defined and $C_{\max , \mathrm{u}} / K_{i}$ is one of the criteria considered [122]. In one study an $I_{\max , \mathrm{u}} / K_{i}>1$ was suggested as a cut-off limit for P-gp-mediated DDIs at the $\mathrm{BBB}$, and by another group $I_{\max , \mathrm{u}} / K_{i}<0.1$ was proposed as a cut-off for ruling out significant P-gp-mediated DDI at the BBB in humans [123]. By analogy, a MRP5 inhibitionmediated DDI at the BBB by cladribine is unlikely. No data are available on cladribine-mediated inhibition of MATE1 or MATE2K.

\subsubsection{Influx/Uptake Transporters}

In vitro inhibition of the hepatic uptake transporters OATP1B1, OATP1B3, and OCT1 by cladribine was examined in stably transfected HEK cell lines for each of these human hepatic uptake transporters. Cladribine, at concentrations of $12 \mu \mathrm{M}$ and $60 \mu \mathrm{M}$, did not show any uptake inhibition of the employed transporter specific substrates $\left({ }^{3} \mathrm{H}\right.$-estrone sulfate, ${ }^{3} \mathrm{H}$-sulfobromophthalein, and ${ }^{3} \mathrm{H}-1$-methyl-4-phenylpyridinium iodide) [data on file, Study Report 15-GR028-P0; Merck KGaA].

These results are consistent with published data by Marada and colleagues who screened a panel of antineoplastic drugs for their inhibitory potential of OATP1B1 and OATP1B3 (in stably transfected HEK cells) using $\left[{ }^{3} \mathrm{H}\right]$-estrone 3 -sulfate and $\left[{ }^{3} \mathrm{H}\right]$-cholecystokinin octapeptide as OATP1B1 and OATP1B3 substrates, respectively [91]. This study showed that neither the OATP1B1-mediated uptake of $\left[{ }^{3} \mathrm{H}\right]$-estrone 3 -sulfate nor the OATP1B3-mediated uptake of $\left[{ }^{3} \mathrm{H}\right]$-cholecystokinin octapeptide were inhibited by cladribine at a concentration of $100 \mu \mathrm{M}$ [91]. Similarly, Yamaguchi and co-workers demonstrated the absence of OATP1B3 inhibition by cladribine at concentrations of 5 and $20 \mu \mathrm{M}$, by using HEK293 cells overexpressing OATP1B3 using chenodeoxycholyl-(Ne-NBD)-lysine as a probe substrate [124]. Taken together, there is robust evidence from various sources available that cladribine does not inhibit OATP1B1 and OATP1B3 up to concentrations of $100 \mu \mathrm{M}$.

In vitro inhibition of renal uptake transporters OCT2, OAT1, and OAT3 by cladribine was tested in transporter overexpressing cell lines. Interestingly, a slight stimulation (35\%) of OCT2-mediated metformin transport was observed at $33 \mu \mathrm{M}$ of cladribine. Modest in vitro inhibition of OAT1 and OAT3 was observed; however, this was too low to determine $\mathrm{IC}_{50}$ values.

Marada et al. examined various antineoplastic drugs, including cladribine, for their inhibition of OAT2-mediated ${ }^{3} \mathrm{H}$-cGMP uptake in stably transfected HEK-293 cells using probenecid, a well-known inhibitor of OATs, as a control [125]. Cladribine $(100 \mu \mathrm{M})$ did not inhibit OAT2-mediated ${ }^{3} \mathrm{H}-\mathrm{cGMP}$ uptake to a significant extent [125].

Toh et al. [126] examined the inhibitory effects of 101 anticancer drugs, including cladribine, from a clinical drug 
library on hOAT4 transport activity. The studies were carried out in hOAT4-expressing human kidney HEK-293 cells and human placenta BeWo cells by using ${ }^{3} \mathrm{H}$-estrone sulfate as a prototypical OAT4 substrate and probenecid as an OAT4 inhibitor control [126]. Cladribine $(10 \mu \mathrm{M})$ only showed a modest inhibition of ${ }^{3} \mathrm{H}$-estrone sulfate uptake by about $25 \%$, which was too low to determine an $\mathrm{IC}_{50}$ value [126]. Taken together, no clinically significant inhibition of the renal uptake transporters OCT2, OAT1, OAT2, OAT3, and OAT4 by cladribine is to be expected.

Regarding potential CNT inhibition by cladribine, there are no published or proprietary data on CNT1 available, while one study reported weak inhibition of CNT2 of $\left[{ }^{3} \mathrm{H}\right]$ inosine uptake in HeLa cells expressing CNT2 with an $\mathrm{IC}_{50}$ of $371 \mu \mathrm{M}$ [127]. In general, no high-affinity inhibitors of CNTs are known as marketed medicinal products. This renders it unlikely that cladribine may confer clinically relevant CNT1 or CNT2 inhibition, also because cladribine has not been shown to be a substrate of CNT1 [51] and has been categorized as a low-affinity substrate of CNT2 [52, 53]. Conflicting data have been reported on cladribine-mediated inhibition of CNT3. In Saccharomyces cerevisiae cells overexpressing CNT3, cladribine inhibited adenosine transport with a $K_{i}$ of $17 \mu \mathrm{M}$ [53], and in oocytes overexpressing CNT3 a $K_{i}$ of $274 \mu \mathrm{M}$ was observed using inosine as a probe [54]. Considering the maximum unbound cladribine exposure $\left(C_{\mathrm{max}, \mathrm{ss}, \mathrm{u}}\right)$ of about $0.112 \mu \mathrm{M}$ that is achieved with recommended clinical doses, in vivo inhibition of CNT2 and CNT3 by cladribine can be excluded [17]. However, a possible intestinal CNT3 in vivo inhibition cannot be confidently ruled out based on the data reported by King and co-workers [53], as CNT3 is expressed at the apical/luminal membrane of enterocytes [47]. However, owing to the 3-h time separation of cladribine dosing from other orally administered drug products, as per the cladribine label [5], the likelihood of a CNT3-based absorption interaction with cladribine in clinical practice is unlikely as CNT3 inhibition by cladribine would be expected to be competitive, concentration related, and hence transient.

Cladribine inhibited ENT1 and ENT2 activity in S. cerevisiae cells overexpressing human ENT1 or ENT2 using adenosine as probe with a $K_{i}$ of $36 \mu \mathrm{M}$ and $50 \mu \mathrm{M}$, respectively [53]. A recent study determined $\mathrm{IC}_{50}$ values of cladribine for ENT1-mediated and ENT2-mediated inhibition of ${ }^{3} \mathrm{H}$-uridine uptake in HeLa cells with ENT expression limited to ENT1 or ENT2 with $67.26 \mu \mathrm{M}$ and $40.15 \mu \mathrm{M}$, respectively [68]. Both transporters are expressed in the sinusoi$\mathrm{dal} /$ basolateral membrane of hepatocytes [36]. Applying the same criteria as for other hepatic uptake transporters such as OATP1B1, OATP1B3, and OCT1, hepatic inhibition is likely not significant clinically. Similarly, ENT1 and ENT2 are expressed in the basolateral membrane of renal proximal tubule cells [106]. Application of the same criteria as for co-localized uptake transporters (OAT1, OAT2, OCT2) inhibition of ENT1 and ENT2 by cladribine is likely not clinically significant. Considering the maximum systemic cladribine concentrations achieved with recommended doses, a systemic in vivo inhibition of ENT1 and ENT2 by cladribine can be excluded [17]. Thus, taken together, a clinically significant cladribine-mediated inhibition of hepatic or renal uptake, or translocation through the BBB or BCSFB of coadministered ENT1 and ENT2 substrate drugs is also not expected in clinical practice.

\subsubsection{Summary of the Transporter Inhibitor Characteristics of Cladribine}

Taken together, available in vitro studies examining the inhibitor characteristics of cladribine for a total of 13 major $\mathrm{ABC}, \mathrm{SLC}$, and CNT/ENT transporters indicate that cladribine does not confer systemic inhibition of any of these transporters in vivo (Tables 4, 5, and 6). There are some remaining uncertainties regarding the possibility of intestinal inhibition of P-gp, CNT3, or ENT1 and ENT2, which cannot be entirely ruled out because of inconsistencies or a paucity of available data. However, the regulatory cutoff criteria for intestinal absorption interactions only apply to administration scenarios in which drug products are coadministered at the same time and not for a 3-h time separation scenario between the administration of two oral drug products, which minimizes the possibility of competitive transporter-based absorption interactions that are expected to be concentration dependent and thus, transient.

The absence of ABC, SLC, and CNT transporter inhibition by cladribine does not only indicate absence of a transporter-based drug-interaction susceptibility; a broader systems-pharmacological view on these transporter families reveals key biological roles of these transporters in the handling of diverse endogenous substrates (e.g., bilirubin, creatinine), metabolites, antioxidants, signaling molecules, hormones, nutrients, and neurotransmitters [80]. Thus, the absence of transporter-inhibiting product characteristics is to be considered a general, albeit often unrecognized, safety attribute of a medicinal product.

\subsection{Transporter Inducer Characteristics of Cladribine}

Regulation of drug transporters is complex and not yet fully understood. It is known, however, that comparable to the induction of CYP enzymes by activation of specific nuclear receptors such as pregnane $X$ receptor and the constitutive androstane receptor, certain transporters such as $\mathrm{P}$-gp are also inducible through mechanisms similar to those for CYP enzymes [17, 128]. Because of these similarities, information from CYP3A induction studies can inform P-gp 
induction considerations. Cladribine appears to have no clinically meaningful inductive effect on CYP1A2, CYP2B6, and CYP3A4 enzymes, although the results from two separate in vitro studies in human hepatocytes were not entirely consistent and conclusive [20]. A currently ongoing clinical drug-interaction study examining the effects of cladribine tablets on the pharmacokinetics of an ethinyl estradiol/ levonorgestrel-containing oral contraceptive (Microgynon ${ }^{\circledR}$ ) will ultimately address the question, in terms of whether cladribine might confer some CYP3A-inducing effects in vivo (ClinicalTrials.gov Identifier: NCT03745144).

\section{Conclusions}

As a nucleoside analog drug, absorption, distribution, and renal excretion of cladribine relies on a variety of uptake and efflux transport proteins. Ample information is available on the transporter substrate and inhibitor characteristics of cladribine. This information is comprehensive for concentrative and equilibrative NTs, and includes many key $\mathrm{ABC}$ and SLC transporter proteins known to play important roles in the disposition of nucleoside analog drugs, drug interactions, and/or side effects. Among the key ABC efflux transporters, only BCRP has been shown to be an efficient transporter of cladribine, while P-gp does not transport cladribine well. Intestinal absorption, distribution throughout the body, and intracellular uptake of cladribine appear to be exclusively mediated by equilibrative and concentrative NTs, specifically by ENT1, ENT2, ENT4, CNT2 (low affinity), and CNT3. Renal excretion of cladribine includes active tubular secretion, which appears to be most likely driven by BCRP, ENT1, and P-gp. The latter may play a role despite its poor cladribine transport efficiency in view of the high renal abundance of P-gp. There is no evidence that SLC uptake transporters, such as OATPs, OATs, and OCTs, are involved in the transport of cladribine. Available in vitro studies examining the inhibitor characteristics of cladribine for a total of 13 major ABC, SLC, and CNT transporters indicate that in vivo inhibition of any of these transporters by cladribine is unlikely.

Acknowledgements The authors thank the patients, investigators, and co-investigators involved in the Cladribine Tablets clinical trial program, as well as study teams at the participating centers, at Merck KGaA, Darmstadt, Germany, and at Merck Serono SA, Switzerland. The authors acknowledge Ella Palmer of inScience Communications, Chester, UK, for medical writing support, funded by Merck KGaA (Darmstadt, Germany).

\section{Declarations}

Funding The in vitro studies summarized in this report were sponsored by Merck Healthcare KGaA (CrossRef Funder ID: 10.13039/100009945).
Conflicts of Interest/Competing Interests Robert Hermann served as an external clinical pharmacology expert advisor for various aspects in the clinical development of cladribine, and received financial support for research, consulting, and training services from Merck Healthcare KGaA, Darmstadt, Germany. Peter Krajcsi served as an external pharmacology expert advisor for in vitro transporter studies. He is a co-founder of Habilitas Kft, which received financial support for generation of an Internal Transporter Report from Merck Healthcare KGaA, Darmstadt, Germany. He was also an employee of Solvo Biotechnology, Budapest, Hungary, outside this advisory work. Annick Seithel-Keuth, Markus Fluck, and Afrim Bytyqi are employees of Merck Healthcare KGaA, Darmstadt, Germany. Andrew Galazka was an employee of Ares Trading SA, Eysins, Switzerland, an affiliate of Merck KGaA at the time of the study, and is currently a consultant to Merck Healthcare KGaA, Darmstadt, Germany. Alain Munafo is an employee of the Merck Institute of Pharmacometrics, Lausanne, Switzerland, an affiliate of Merck KGaA.

Ethics Approval Not applicable.

Consent to Participate Not applicable.

Consent for Publication Not applicable.

Availability of Data and Material Any requests for data by qualified scientific and medical researchers for legitimate research purposes will be subject to Merck Healthcare KGaA's data sharing policy. All requests should be submitted in writing to Merck Healthcare KGaA's data sharing portal: https://www.merckgroup.com/en/research/our-approach-toresearch-and-development/healthcare/clinical-trials/commitment-respo nsible-data-sharing.html. When Merck Healthcare KGaA has a coresearch, co-development, co-marketing, or co-promotion agreement, or when the product has been out-licensed, the responsibility for disclosure might be dependent on the agreement between parties. Under these circumstances, Merck KGaA will endeavor to gain agreement to share data in response to requests.

Code Availability Not applicable.

Authors' Contributions All authors contributed to the concept, design, and critical review of the manuscript, and approved the final version for submission.

Open Access This article is licensed under a Creative Commons Attribution-NonCommercial 4.0 International License, which permits any non-commercial use, sharing, adaptation, distribution and reproduction in any medium or format, as long as you give appropriate credit to the original author(s) and the source, provide a link to the Creative Commons licence, and indicate if changes were made. The images or other third party material in this article are included in the article's Creative Commons licence, unless indicated otherwise in a credit line to the material. If material is not included in the article's Creative Commons licence and your intended use is not permitted by statutory regulation or exceeds the permitted use, you will need to obtain permission directly from the copyright holder. To view a copy of this licence, visit http://creativecommons.org/licenses/by-nc/4.0/.

\section{References}

1. The Multiple Sclerosis International Federation, atlas of MS, 3rd ed. https://www.atlasofms.org/map/global/epidemiology/ number-of-people-with-ms. Accessed Jun 2021 
2. Giovannoni G, Butzkueven H, Dhib-Jalbut S, Hobart J, Kobelt G, Pepper G, et al. Brain health: time matters in multiple sclerosis. Mult Scler Relat Disord. 2016;9(Suppl. 1):S5-48.

3. Compston A, Coles A. Multiple sclerosis. Lancet. 2008;372(9648):1502-17.

4. Giovannoni G, Comi G, Cook S, Rammohan K, Rieckmann P, Sørensen PS, et al. A placebo-controlled trial of oral cladribine for relapsing multiple sclerosis. N Engl J Med. 2010;362(5):416-26.

5. EMA. Mavenclad $10 \mathrm{mg}$ tablets: summary of product characteristics (SPC). https://www.ema.europa.eu/en/documents/produ ct-information/mavenclad-epar-product-information_en.pdf. Accessed Jun 2021

6. Baker D, Herrod SS, Alvarez-Gonzalez C, Zalewski L, Albor $\mathrm{C}$, Schmierer K. Both cladribine and alemtuzumab may effect MS via B-cell depletion. Neurol Neuroimmunol Neuroinflamm. 2017;4(4): e360.

7. Stuve O, Soelberg Soerensen P, Leist T, Giovannoni G, Hyvert Y, Damian D, et al. Effects of cladribine tablets on lymphocyte subsets in patients with multiple sclerosis: an extended analysis of surface markers. Ther Adv Neurol Disord. 2019;12:1756286419854986.

8. Ceronie B, Jacobs BM, Baker D, Dubuisson N, Mao Z, Ammoscato $\mathrm{F}$, et al. Cladribine treatment of multiple sclerosis is associated with depletion of memory B cells. J Neurol. 2018;265(5):1199-209.

9. Giovannoni G. Disease-modifying treatments for early and advanced multiple sclerosis: a new treatment paradigm. Curr Opin Neurol. 2018;31(3):233-43.

10. Menzin J, Caon C, Nichols C, White LA, Friedman M, Pill MW. Narrative review of the literature on adherence to disease-modifying therapies among patients with multiple sclerosis. J Manag Care Pharm. 2013;19(1 Suppl. A):S24-40.

11. Beutler E. Cladribine (2-chlorodeoxyadenosine). Lancet. 1992;340(8825):952-6.

12. Comi G, Hartung HP, Kurukulasuriya NC, Greenberg SJ, Scaramozza M. Cladribine tablets for the treatment of relapsing-remitting multiple sclerosis. Expert Opin Pharmacother. 2013;14(1):123-36.

13. Salvat C, Curchod M, Guedj E, Peixoto H, Guerrier, et al. Cellular expression profiling of genes involved in the cladribine metabolic pathway: insights into mechanism of action in multiple sclerosis. Mult Scler. 2009;15(9_suppl):5-150.

14. Soelberg-Sorensen P, Dangond F, Hicking C, Giovannoni G. P1141: innate immune cell counts in patients with relapsingremitting multiple sclerosis (RRMS) treated with cladribine tablets $3.5 \mathrm{mg} / \mathrm{kg}$ in CLARITY and CLARITY extension. Mult Scler. 2017;23:598

15. Comi G, Cook S, Giovannoni G, Rieckmann P, Sorensen PS, Vermersch P, et al. Effect of cladribine tablets on lymphocyte reduction and repopulation dynamics in patients with relapsing multiple sclerosis. Mult Scler Relat Disord. 2019;29:168-74.

16. Benet LZ, Broccatelli F, Oprea TI. BDDCS applied to over 900 drugs. AAPS J. 2011;13(4):519-47.

17. European Medicines Agency (EMA). Guideline on the investigation of drug interactions. Committee for Human Medicinal Products (CHMP). CPMP/EWP/560/95/Rev. 1 Corr. 2; 2012. pp 1-59. https://www.ema.europa.eu/en/documents/scientific-guide line/guideline-investigation-drug-interactions-revision-1_en.pdf. Accessed 11 Aug 2021.

18. US Department of Health and Human Services; Food and Drug Administration; Center for Drug Evaluation and Research (CDER). In vitro drug interaction studies: cytochrome P450 enzyme- and transporter-mediated drug interactions. Guidance for industry; 2020. pp 1-46. https://www.fda.gov/regulatoryinformation/search-fda-guidance-documents/vitro-drug-inter action-studies-cytochrome-p450-enzyme-and-transporter-media ted-drug-interactions. Accessed 11 Aug 2021.

19. Ministry of Labor and Welfare. Guideline on drug interaction for drugdevelopment and appropriate provision of information, notification No.0723-4, pharmaceutical evaluation division, pharmaceuticals safety and environ-mental Health bureau, Japan. July 23, 2018. https://www.pmda.go.jp/files/000228122. pdf. Accessed 11 Aug 2021.

20. Hermann R, Karlsson MO, Novakovic AM, Terranova N, Fluck M, Munafo A. The clinical pharmacology of cladribine tablets for the treatment of relapsing multiple sclerosis. Clin Pharmacokinet. 2019;58(3):283-97.

21. Zhang D, Zhu M, Humphreys WG. Drug metabolism in drug design and development: basic concepts and practice. Hoboken: Wiley; 2008.

22. Choi $\mathrm{YH}, \mathrm{Yu} \mathrm{AM} . \mathrm{ABC}$ transporters in multidrug resistance and pharmacokinetics, and strategies for drug development. Curr Pharm Des. 2014;20(5):793-807.

23. Giacomini KM, Huang SM. Transporters in drug development and clinical pharmacology. Clin Pharmacol Ther. 2013;94(1):3-9.

24. Jani M, Ambrus C, Magnan R, Jakab KT, Beéry E, Zolnerciks JK, et al. Structure and function of BCRP, a broad specificity transporter of xenobiotics and endobiotics. Arch Toxicol. 2014;88(6):1205-48.

25. Giraud C, Manceau S, Treluyer JM. ABC transporters in human lymphocytes: expression, activity and role, modulating factors and consequences for antiretroviral therapies. Expert Opin Drug Metab Toxicol. 2010;6(5):571-89.

26. Chaudhary PM, Mechetner EB, Roninson IB. Expression and activity of the multidrug resistance P-glycoprotein in human peripheral blood lymphocytes. Blood. 1992;80(11):2735-9.

27. Oselin K, Mrozikiewicz PM, Pähkla R, Roots I. Quantitative determination of the human MRP1 and MRP 2 mRNA expression in FACS-sorted peripheral blood CD4+, CD8+, CD19+, and CD56+ cells. Eur J Haematol. 2003;71(2):119-23.

28. Lund M, Petersen TS, Dalhoff KP. Clinical implications of P-glycoprotein modulation in drug-drug interactions. Drugs. 2017;77(8):859-83.

29. Neumanova Z, Cerveny L, Greenwood SL, Ceckova M, Staud F. Effect of drug efflux transporters on placental transport of antiretroviral agent abacavir. Reprod Toxicol. 2015;57:176-82.

30. de Wolf C, Jansen R, Yamaguchi H, de Haas M, van de Wetering $\mathrm{K}$, Wijnholds J, et al. Contribution of the drug transporter ABCG2 (breast cancer resistance protein) to resistance against anticancer nucleosides. Mol Cancer Ther. 2008;7(9):3092-102.

31. Nishimura M, Naito S. Tissue-specific mRNA expression profiles of human ATP-binding cassette and solute carrier transporter superfamilies. Drug Metab Pharmacokinet. 2005;20(6):452-77.

32. Albermann N, Schmitz-Winnenthal FH, Z'Graggen K, Volk C, Hoffmann MM, Haefeli WE, et al. Expression of the drug transporters MDR1/ABCB1, MRP1/ABCC1, MRP2/ABCC2, BCRP/ ABCG2, and PXR in peripheral blood mononuclear cells and their relationship with the expression in intestine and liver. Biochem Pharmacol. 2005;70(6):949-58.

33. Ma Z, Yang X, Jiang T, Bai M, Zheng C, Zeng S, et al. Multiple SLC and ABC transporters contribute to the placental transfer of entecavir. Drug Metab Dispos. 2017;45(3):269-78.

34. Feng B, West M, Patel NC, Wager T, Hou X, Johnson J, et al. Validation of human MDR1-MDCK and BCRP-MDCK cell lines to improve the prediction of brain penetration. J Pharm Sci. 2019;108(7):2476-83.

35. Takenaka K, Morgan JA, Scheffer GL, Adachi M, Stewart CF, Sun D, et al. Substrate overlap between Mrp4 and Abcg2/Bcrp affects purine analogue drug cytotoxicity and tissue distribution. Cancer Res. 2007;67(14):6965-72. 
36. Boswell-Casteel RC, Hays FA. Equilibrative nucleoside transporters: a review. Nucleosides Nucleotides Nucleic Acids. 2017;36(1):7-30.

37. Deeley RG, Westlake C, Cole SP. Transmembrane transport of endo- and xenobiotics by mammalian ATP-binding cassette multidrug resistance proteins. Physiol Rev. 2006;86(3):849-99.

38. Fukuda Y, Schuetz JD. ABC transporters and their role in nucleoside and nucleotide drug resistance. Biochem Pharmacol. 2012;83(8):1073-83.

39. Zhang YK, Wang YJ, Gupta P, Chen ZS. Multidrug resistance proteins (MRPs) and cancer therapy. AAAPS J. 2015; 17(4):802-12.

40. Reid G, Wielinga P, Zelcer N, De Haas M, Van Deemter L, Wijnholds J, et al. Characterization of the transport of nucleoside analog drugs by the human multidrug resistance proteins MRP4 and MRP5. Mol Pharmacol. 2003;63(5):1094-103.

41. Chen ZS, Lee K, Kruh GD. Transport of cyclic nucleotides and estradiol 17-beta-D-glucuronide by multidrug resistance protein 4. Resistance to 6-mercaptopurine and 6-thioguanine. J Biol Chem. 2001;276(36):33747-54

42. Nies AT, Damme K, Kruck S, Schaeffeler E, Schwab M. Structure and function of multidrug and toxin extrusion proteins (MATEs) and their relevance to drug therapy and personalized medicine. Arch Toxicol. 2016;90(7):1555-84

43. Hillgren KM, Keppler D, Zur AA, Giacomini KM, Stieger B, Cass CE, et al. Emerging transporters of clinical importance: an update from the International Transporter Consortium. Clin Pharmacol Ther. 2013;94(1):52-63.

44. König J, Zolk O, Singer K, Hoffmann C, Fromm MF. Doubletransfected MDCK cells expressing human OCT1/MATE1 or OCT2/MATE1: determinants of uptake and transcellular translocation of organic cations. Br J Pharmacol. 2011;163(3):546-55.

45. Müller F, König J, Hoier E, Mandery K, Fromm MF. Role of organic cation transporter OCT2 and multidrug and toxin extrusion proteins MATE1 and MATE2-K for transport and drug interactions of the antiviral lamivudine. Biochem Pharmacol. 2013;86(6):808-15.

46. Reznicek J, Ceckova M, Cerveny L, Müller F, Staud F. Emtricitabine is a substrate of MATE1 but not of OCT1, OCT2, P-gp, BCRP or MRP2 transporters. Xenobiotica. 2017;47(1):77-85.

47. Young JD, Yao SY, Baldwin JM, Cass CE, Baldwin SA. The human concentrative and equilibrative nucleoside transporter families, SLC28 and SLC29. Mol Aspects Med. 2013;34(2-3):529-47.

48. Gray JH, Owen RP, Giacomini KM. The concentrative nucleoside transporter family, SLC28. Pflugers Arch. 2004;447(5):728-34.

49. Young JD. The SLC28 (CNT) and SLC29 (ENT) nucleoside transporter families: a 30-year collaborative odyssey. Biochem Soc Trans. 2016;44(3):869-76.

50. Smith KM, Ng AM, Yao SY, Labedz KA, Knaus EE, Wiebe LI, et al. Electrophysiological characterization of a recombinant human Na+-coupled nucleoside transporter (hCNT1) produced in Xenopus oocytes. J Physiol. 2004;558(Pt 3):807-23.

51. Lang TT, Young JD, Cass CE. Interactions of nucleoside analogs, caffeine, and nicotine with human concentrative nucleoside transporters 1 and 2 stably produced in a transport-defective human cell line. Mol Pharmacol. 2004;65(4):925-33.

52. Owen RP, Badagnani I, Giacomini KM. Molecular determinants of specificity for synthetic nucleoside analogs in the concentrative nucleoside transporter, CNT2. J Biol Chem. 2006;281(36):26675-82.

53. King KM, Damaraju VL, Vickers MF, Yao SY, Lang T, Tackaberry TE, et al. A comparison of the transportability, and its role in cytotoxicity, of clofarabine, cladribine, and fludarabine by recombinant human nucleoside transporters produced in three model expression systems. Mol Pharmacol. 2006;69(1):346-53.
54. Badagnani I, Chan W, Castro RA, Brett CM, Huang CC, Stryke $\mathrm{D}$, et al. Functional analysis of genetic variants in the human concentrative nucleoside transporter 3 (CNT3; SLC28A3). Pharmacogenomics J. 2005;5(3):157-65.

55. Ritzel MW, Ng AM, Yao SY, Graham K, Loewen SK, Smith $\mathrm{KM}$, et al. Molecular identification and characterization of novel human and mouse concentrative $\mathrm{Na}$--nucleoside cotransporter proteins (hCNT3 and mCNT3) broadly selective for purine and pyrimidine nucleosides (system cib). J Biol Chem. 2001;276(4):2914-27.

56. Baldwin SA, Beal PR, Yao SY, King AE, Cass CE, Young JD. The equilibrative nucleoside transporter family, SLC29. Pflugers Arch. 2004;447(5):735-43.

57. Grane-Boladeras N, Williams D, Tarmakova Z, Stevanovic K, Villani LA, Mehrabi P, et al. Oligomerization of equilibrative nucleoside transporters: a novel regulatory and functional mechanism involving PKC and PP1. FASEB J. 2019;33(3):3841-50.

58. Govindarajan R, Endres CJ, Whittington D, LeCluyse E, PastorAnglada M, Tse CM, et al. Expression and hepatobiliary transport characteristics of the concentrative and equilibrative nucleoside transporters in sandwich-cultured human hepatocytes. Am J Physiol Gastrointest Liver Physiol. 2008;295(3):G570-80.

59. Barnes K, Dobrzynski H, Foppolo S, Beal PR, Ismat F, Scullion ER, et al. Distribution and functional characterization of equilibrative nucleoside transporter-4, a novel cardiac adenosine transporter activated at acidic pH. Circ Res. 2006;99(5):510-9.

60. Tandio D, Vilas G, Hammond JR. Bidirectional transport of 2-chloroadenosine by equilibrative nucleoside transporter 4 (hENT4): Evidence for allosteric kinetics at acidic pH. Sci Rep. 2019;9(1):13555.

61. Engel K, Zhou M, Wang J. Identification and characterization of a novel monoamine transporter in the human brain. J Biol Chem. 2004;279(48):50042-9.

62. Zhou M, Engel K, Wang J. Evidence for significant contribution of a newly identified monoamine transporter (PMAT) to serotonin uptake in the human brain. Biochem Pharmacol. 2007;73(1):147-54.

63. Xia L, Engel K, Zhou M, Wang J. Membrane localization and pH-dependent transport of a newly cloned organic cation transporter (PMAT) in kidney cells. Am J Physiol Renal Physiol. 2007;292(2):F682-90.

64. Minuesa G, Purcet S, Erkizia I, Molina-Arcas M, Bofill M, Izquierdo-Useros N, et al. Expression and functionality of anti-human immunodeficiency virus and anticancer drug uptake transporters in immune cells. J Pharmacol Exp Ther. 2008;324(2):558-67.

65. Dos Santos-Rodrigues A, Grañé-Boladeras N, Bicket A, Coe IR. Nucleoside transporters in the purinome. Neurochem Int. 2014;73:229-37.

66. Wright AM, Gati WP, Paterson AR. Enhancement of retention and cytotoxicity of 2-chlorodeoxyadenosine in cultured human leukemic lymphoblasts by nitrobenzylthioinosine, an inhibitor of equilibrative nucleoside transport. Leukemia. 2000;14(1):52-60.

67. King KM, Cass CE. Membrane transport of 2-chloro2 -deoxyadenosine and 2-chloro-2'-arabinofluoro-2'deoxyadenosine is required for cytotoxicity. Proc Amer Assoc Cancer Res. 1994;35:A3436.

68. Miller SR, Zhang X, Hau RK, Jilek JL, Jennings EQ, Galligan JJ, et al. Predicting drug interactions with human equilibrative nucleoside transporters 1 and 2 using functional knockout cell lines and Bayesian modeling. Mol Pharmacol. 2021;99(2):147-62.

69. Ho HTB, Wang J. The nucleoside transporters CNT and ENT. In: You G, Morris ME (eds) Drug transporters: molecular characterization and role in drug disposition. Wiley, Hoboken; 2014. pp 107-126.

70. Li H, Smolen GA, Beers LF, Xia L, Gerald W, Wang J, et al. Adenosine transporter ENT4 is a direct target of EWS/WT1 
translocation product and is highly expressed in desmoplastic small round cell tumor. PLoS ONE. 2008;3(6): e2353.

71. Giacomini KM, Huang SM, Tweedie DJ, Benet LZ, Brouwer KL, Chu X, et al. Membrane transporters in drug development. Nat Rev Drug Discov. 2010;9(3):215-36.

72. Hagenbuch B, Gui C. Xenobiotic transporters of the human organic anion transporting polypeptides (OATP) family. Xenobiotica. 2008;38(7-8):778-801.

73. Drenberg CD, Paugh SW, Pounds SB, Shi L, Orwick SJ, Li L, et al. Inherited variation in OATP1B1 is associated with treatment outcome in acute myeloid leukemia. Clin Pharmacol Ther. 2016;99(6):651-60.

74. Wagner DJ, Hu T, Wang J. Polyspecific organic cation transporters and their impact on drug intracellular levels and pharmacodynamics. Pharmacol Res. 2016;111:237-46.

75. Koepsell H, Lips K, Volk C. Polyspecific organic cation transporters: structure, function, physiological roles, and biopharmaceutical implications. Pharm Res. 2007;24(7):1227-51.

76. Umehara KI, Iwatsubo T, Noguchi K, Kamimura H. Functional involvement of organic cation transporter1 (OCT1/Oct1) in the hepatic uptake of organic cations in humans and rats. Xenobiotica. 2007;37(8):818-31.

77. Moss DM, Liptrott NJ, Siccardi M, Owen A. Interactions of antiretroviral drugs with the SLC22A1 (OCT1) drug transporter. Front Pharmacol. 2015;6:78.

78. Jung N, Lehmann C, Rubbert A, Schömig E, Fätkenheuer G, Hartmann P, et al. Organic cation transporters OCT1 and OCT2 determine the accumulation of lamivudine in CD4 cells of HIV-infected patients. Infection. 2013;41(2):379-85.

79. Burckhardt G. Drug transport by organic anion transporters (OATs). Pharmacol Ther. 2012;136(1):106-30.

80. Nigam SK. What do drug transporters really do? Nat Rev Drug Discov. 2015;14(1):29-44.

81. Nigam SK, Bush KT, Martovetsky G, Ahn SY, Liu HC, Richard E, et al. The organic anion transporter (OAT) family: a systems biology perspective. Physiol Rev. 2015;95(1):83-123.

82. Roth M, Obaidat A, Hagenbuch B. OATPs, OATs and OCTs: the organic anion and cation transporters of the SLCO and SLC22A gene superfamilies. Br J Pharmacol. 2012;165(5):1260-87.

83. Hosoyamada M, Sekine T, Kanai Y, Endou H. Molecular cloning and functional expression of a multispecific organic anion transporter from human kidney. Am J Physiol. 1999;276(1):F122-8.

84. Motohashi H, Sakurai Y, Saito H, Masuda S, Urakami Y, Goto $\mathrm{M}$, et al. Gene expression levels and immunolocalization of organic ion transporters in the human kidney. J Am Soc Nephrol. 2002;13(4):866-74.

85. Takeda M, Noshiro R, Onozato ML, Tojo A, Hasannejad H, Huang XL, et al. Evidence for a role of human organic anion transporters in the muscular side effects of HMG-CoA reductase inhibitors. Eur J Pharmacol. 2004;483(2-3):133-8.

86. Cano-Soldado P, Pastor-Anglada M. Transporters that translocate nucleosides and structural similar drugs: structural requirements for substrate recognition. Med Res Rev. 2012;32(2):428-57.

87. Mandíková J, Volková M, Pávek P, Česnek M, Janeba Z, Kubíček V, et al. Interactions with selected drug renal transporters and transporter-mediated cytotoxicity in antiviral agents from the group of acyclic nucleoside phosphonates. Toxicology. 2013;311(3):135-46.

88. Enomoto A, Takeda M, Shimoda M, Narikawa S, Kobayashi Y, Kobayashi Y, et al. Interaction of human organic anion transporters 2 and 4 with organic anion transport inhibitors. J Pharmacol Exp Ther. 2002;301(3):797-802.

89. Cheng Y, Vapurcuyan A, Shahidullah M, Aleksunes LM, Pelis RM. Expression of organic anion transporter 2 in the human kidney and its potential role in the tubular secretion of guanine-containing antiviral drugs. Drug Metab Dispos. 2012;40(3):617-24

90. Kobayashi Y, Ohshiro N, Sakai R, Ohbayashi M, Kohyama N, Yamamoto T. Transport mechanism and substrate specificity of human organic anion transporter 2 (hOat2 [SLC22A7]). J Pharm Pharmacol. 2005;57(5):573-8.

91. Marada VV, Flörl S, Kühne A, Burckhardt G, Hagos Y. Interaction of human organic anion transporter polypeptides 1B1 and 1B3 with antineoplastic compounds. Eur J Med Chem. 2015;6(92):723-31.

92. Cha SH, Sekine T, Fukushima JI, Kanai Y, Kobayashi Y, Goya $\mathrm{T}$, et al. Identification and characterization of human organic anion transporter 3 expressing predominantly in the kidney. Mol Pharmacol. 2001;59(5):1277-86.

93. Bleasby K, Castle JC, Roberts CJ, Cheng C, Bailey WJ, Sina JF, et al. Expression profiles of 50 xenobiotic transporter genes in humans and pre-clinical species: a resource for investigations into drug disposition. Xenobiotica. 2006;36(10-11):963-88.

94. Babu E, Takeda M, Narikawa S, Kobayashi Y, Enomoto A, Tojo A, et al. Role of human organic anion transporter 4 in the transport of ochratoxin A. Biochim Biophys Acta. 2002;1590(1-3):64-75.

95. Ekaratanawong S, Anzai N, Jutabha P, Miyazaki H, Noshiro R, Takeda M, et al. Human organic anion transporter 4 is a renal apical organic anion/dicarboxylate exchanger in the proximal tubules. J Pharmacol Sci. 2004;94(3):297-304.

96. Ugele B, St-Pierre MV, Pihusch M, Bahn A, Hantschmann P. Characterization and identification of steroid sulfate transporters of human placenta. Am J Physiol Endocrinol Metab. 2003b;284(2):E390-8.

97. Takeda M, Khamdang S, Narikawa S, Kimura H, Kobayashi Y, Yamamoto T, et al. Human organic anion transporters and human organic cation transporters mediate renal antiviral transport. J Pharmacol Exp Ther. 2002;300(3):918-24.

98. Hiratochi M, Tatani K, Shimizu K, Kuramochi Y, Kikuchi N, Kamada N, et al. Hypouricemic effects of novel concentrative nucleoside transporter 2 inhibitors through suppressing intestinal absorption of purine nucleosides. Eur J Pharmacol. 2012;690(1-3):183-91.

99. Senyavina NV, Gerasimenko TN, Fomicheva KA, Tonevitskaya SA, Kaprin AD. Localization and expression of nucleoside transporters ENT1 and ENT2 in polar cells of intestinal epithelium. Bull Exp Biol Med. 2016;160(6):771-4.

100. Shugarts S, Benet LZ. The role of transporters in the pharmacokinetics of orally administered drugs. Pharm Res. 2009;26(9):2039-54.

101. Drozdzik M, Busch D, Lapczuk J, Müller J, Ostrowski M, Kurzawski M, et al. Protein abundance of clinically relevant drug transporters in the human liver and intestine: a comparative analysis in paired tissue specimens. Clin Pharmacol Ther. 2019;105(5):1204-12.

102. Li L, Wright J, Budow A, Bhoopathy S, Owen AJ. Development of a human cell-based BCRP inhibition assay using CellPort CPT-P1 cell monolayers and cladribine as the probe substrate [poster W3008]. In: AAPS drug transporters workshop; San Diego Convention Center, San Diego, California. November 2-6 2014.

103. Vildhede A, Wiśniewski JR, Norén A, Karlgren M, Artursson P. Comparative proteomic analysis of human liver tissue and isolated hepatocytes with a focus on proteins determining drug exposure. J Proteome Res. 2015;14(8):3305-14.

104. Savic RM, Novakovic AM, Ekblom M, Munafo A, Karlsson MO. Population pharmacokinetics of cladribine in patients with multiple sclerosis. Clin Pharmacokinet. 2017;56(10):1245-53.

105. Damaraju VL, Elwi AN, Hunter C, Carpenter P, Santos C, Barron GM, et al. Localization of broadly selective equilibrative 
and concentrative nucleoside transporters, hENT1 and hCNT3, in human kidney. Am J Physiol Renal Physiol. 2007;293(1):F200-11.

106. Mangravite LM, Badagnani I, Giacomini KM. Nucleoside transporters in the disposition and targeting of nucleoside analogs in the kidney. Eur J Pharmacol. 2003;479(1-3):269-81.

107. Caetano-Pinto P, Janssen MJ, Gijzen L, Verscheijden L, Wilmer MJ, Masereeuw R. Fluorescence-based transport assays revisited in a human renal proximal tubule cell line. Mol Pharm. 2016;13(3):933-44.

108. Jenkinson SE, Chung GW, van Loon E, Bakar NS, Dalzell AM, Brown CD. The limitations of renal epithelial cell line HK-2 as a model of drug transporter expression and function in the proximal tubule. Pflugers Arch. 2012;464(6):601-11.

109. Basit A, Radi Z, Vaidya VS, Karasu M, Prasad B. Kidney cortical transporter expression across species using quantitative proteomics. Drug Metab Dispos. 2019;47(8):802-8.

110. Cheung KWK, van Groen BD, Spaans E, van Borselen MD, de Bruijn A, Simons-Oosterhuis Y, et al. A comprehensive analysis of ontogeny of renal drug transporters: mRNA analyses, quantitative proteomics, and localization. Clin Pharmacol Ther. 2019;106(5):1083-92.

111. Fallon JK, Smith PC, Xia CQ, Kim MS. Quantification of four efflux drug transporters in liver and kidney across species using targeted quantitative proteomics by isotope dilution NanoLCMS/MS. Pharm Res. 2016;33(9):2280-8.

112. Oswald S, Müller J, Neugebauer U, Schröter R, Herrmann E, Pavenstädt $\mathrm{H}$, et al. Protein abundance of clinically relevant drug transporters in the human kidneys. Int J Mol Sci. 2019;20(21):5303.

113. Brown CD, Sayer R, Windass AS, Haslam IS, De Broe ME, D'Haese PC, et al. Characterisation of human tubular cell monolayers as a model of proximal tubular xenobiotic handling. Toxicol Appl Pharmacol. 2008;233(3):428-38.

114. Huls M, Brown CD, Windass AS, Sayer R, van den Heuvel JJ, Heemskerk $S$, et al. The breast cancer resistance protein transporter ABCG2 is expressed in the human kidney proximal tubule apical membrane. Kidney Int. 2008;73(2):220-5.

115. Billington S, Salphati L, Hop C, Chu X, Evers R, Burdette $\mathrm{D}$, et al. Interindividual and regional variability in drug transporter abundance at the human blood-brain barrier measured by quantitative targeted proteomics. Clin Pharmacol Ther. 2019;106(1):228-37.

116. Shawahna R, Uchida Y, Declèves X, Ohtsuki S, Yousif S, Dauchy $\mathrm{S}$, et al. Transcriptomic and quantitative proteomic analysis of transporters and drug metabolizing enzymes in freshly isolated human brain microvessels. Mol Pharm. 2011;8(4):1332-41.
117. Uchida Y, Ohtsuki S, Katsukura Y, Ikeda C, Suzuki T, Kamiie $\mathrm{J}$, et al. Quantitative targeted absolute proteomics of human blood-brain barrier transporters and receptors. J Neurochem. 2011;117(2):333-45.

118. Liliemark J. The clinical pharmacokinetics of cladribine. Clin Pharmacokinet. 1997;32(2):120-31.

119. Pastor-Anglada M, Molina-Arcas M, Casado FJ, Bellosillo B, Colomer D, Gil J. Nucleoside transporters in chronic lymphocytic leukaemia. Leukemia. 2004;18(3):385-93.

120. Fernández-Calotti PX, Colomer D, Pastor-Anglada M. Translocation of nucleoside analogs across the plasma membrane in hematologic malignancies. Nucleosides Nucleotides Nucleic Acids. 2011;30(12):1324-40.

121. Nies AT, Jedlitschky G, König J, Herold-Mende C, Steiner HH, Schmitt HP, et al. Expression and immunolocalization of the multidrug resistance proteins, MRP1-MRP6 (ABCC1-ABCC6), in human brain. Neuroscience. 2004;129(2):349-60.

122. Kalvass JC, Polli JW, Bourdet DL, Feng B, Huang SM, Liu X, et al. Why clinical modulation of efflux transport at the human blood-brain barrier is unlikely: the ITC evidence-based position. Clin Pharmacol Ther. 2013;94(1):80-94.

123. Sugimoto H, Hirabayashi H, Amano N, Moriwaki T. Retrospective analysis of P-glycoprotein-mediated drug-drug interactions at the blood-brain barrier in humans. Drug Metab Dispos. 2013;41(4):683-8.

124. Yamaguchi H, Kobayashi M, Okada M, Takeuchi T, Unno M, Abe T, et al. Rapid screening of antineoplastic candidates for the human organic anion transporter OATP1B3 substrates using fluorescent probes. Cancer Lett. 2008;260(1-2):163-9.

125. Marada VV, Flörl S, Kühne A, Müller J, Burckhardt G, Hagos Y. Interaction of human organic anion transporter 2 (OAT2) and sodium taurocholate cotransporting polypeptide (NTCP) with antineoplastic drugs. Pharmacol Res. 2015;91:78-87. https://doi. org/10.1016/j.phrs.2014.11.002

126. Toh MF, Suh W, Wang H, Zhou P, Hu L, You G. Inhibitory effects of chemotherapeutics on human organic anion transporter hOAT4. Int J Biochem Mol Biol. 2016;7(1):11-8.

127. Schaner ME, Wang J, Zhang L, Su SF, Gerstin KM, Giacomini KM. Functional characterization of a human purineselective, Na+-dependent nucleoside transporter (hSPNT1) in a mammalian expression system. J Pharmacol Exp Ther. 1999;289(3):1487-91.

128. Staudinger JL, Madan A, Carol KM, Parkinson A. Regulation of drug transporter gene expression by nuclear receptors. Drug Metab Dispos. 2003;31(5):523-7. 